\title{
Negative Regulation of Oligodendrocyte Differentiation by Galactosphingolipids
}

\author{
Rashmi Bansal, Susan Winkler, and Sheila Bheddah \\ Departments of Pharmacology and Microbiology and Program in Neurological Sciences, University of Connecticut \\ Medical School, Farmington, Connecticut 06030-3205
}

Galactocerebroside and sulfatide, major galactosphingolipid components of oligodendrocyte plasma membranes and myelin, are first expressed at a critical point, when progenitors cease to proliferate and commence terminal differentiation. We showed previously that an antibody to galactocerebroside/ sulfatide arrested terminal differentiation, suggesting a role for these galactolipids in oligodendrocyte differentiation. We have now investigated the differentiation of oligodendrocytes (1) in response to other anti-galactolipid antibodies, showing that anti-sulfatide $\mathrm{O} 4$ but not anti-galactocerebroside $\mathrm{O} 1$ blocks terminal differentiation, perhaps by mimicking an endogenous ligand, and (2) in a transgenic mouse unable to synthesize these lipids because of mutation of the gene for ceramide galactosyltransferase, a key enzyme for galactosphingolipid synthesis. We find that galactosyltransferase mRNA expression begins at the late progenitor [pro-oligodendroblast (Pro-OL)] stage of the lineage and that the late progenitor marker prooligodendroblast antigen is not synthesized in the absence of galactosyltransferase. The principal outcome of the elimination of these galactolipids is a two- to threefold enhancement in the number of terminally differentiated oligodendrocytes both in culture and in vivo. Because the general pattern of differentiation and the level of progenitor proliferation and survival appear to be unaltered in the mutant cultures, we conclude that the increased number of oligodendrocytes is caused by an increased rate and probability of differentiation. In agreement with these two experimental approaches, we present a model in which galactosphingolipids (in particular galactocerebroside and/or sulfatide) act as sensors and/or transmitters of environmental information, interacting with endogenous ligands to function as negative regulators of oligodendrocyte differentiation, monitoring the timely progress of Pro-OLs into terminally differentiating, myelin-producing oligodendrocytes.

Key words: oligodendrocyte; glycosphingolipids; myelin; sulfatide; galactocerebroside; ceramide galactosyltransferase
An understanding of environmental signals that regulate oligodendrocyte (OL) development and of molecules on the OL cell surface through which these signals act is basic to an understanding of both normal OL development and the process of remyelination in demyelinating disease. Oligodendrocytes, the cells of the CNS that produce myelin, proceed through a regulated lineage culminating in the assembly of the components of the myelin membrane (Pfeiffer et al., 1993; Miller, 1996). Briefly, the bipolar early progenitor $(\mathrm{O} 2 \mathrm{~A})$ differentiates into a multipolar late progenitor [pro-oligodendroblast (Pro-OL)] defined by the expression of pro-oligodendroblast antigen (POA) (Bansal et al., 1992), followed by the transient pre-GalC stage (Bansal and Pfeiffer, 1992). The onset of terminal differentiation (immature OL stage) is defined by the synthesis of galactocerebroside (GalC), sulfatide, 2',3'-cyclic nucleotide $3^{\prime}$-phosphohydrolase (CNP), and myelin-associated glycoprotein (MAG). After a short lag, mature

\footnotetext{
Received April 21, 1999; revised June 18, 1999; accepted June 25, 1999.

This work was supported by National Institutes of Health Grant NS 10861. We thank Drs. B. Popko and T. Coetzee (University of North Carolina, Chapel Hill, NC) for providing breeding pairs of CGT-null mice, Drs. W. B. Macklin and B. Fuss (Cleveland Clinic, Cleveland, $\mathrm{OH}$ ) for the generous gift of the PLP cRNA probe, and Dr. P. Fredman (University of Goteborg, Goteborg, Sweden) for the Sulph-1 antibody. We are pleased to acknowledge the contributions of Western blot analysis by J. Farrel, manuscript processing by J. Seagren, and insightful manuscript reviewing by Dr. T. Coetzee. We especially appreciate the valuable advice, help, and encouragement of Dr. S. E. Pfeiffer during the course of this work and the preparation of this manuscript.

Correspondence should be addressed to Dr. Rashmi Bansal, Department of Microbiology, MC-3205, 263 Farmington Avenue, University of Connecticut Medical School, Farmington, CT 06030-3205.

Copyright (C) 1999 Society for Neuroscience 0270-6474/99/197913-12\$05.00/0
}

OLs appear that are characterized by the expression of terminal markers such as myelin basic protein (MBP) and proteolipid protein (PLP) and the production of extensive process networks and myelin-like membranes. The developmental pathway observed in culture is consistent with lineage progression in situ (Hardy and Reynolds, 1991; Warrington and Pfeiffer, 1992) and can be formalized according to the scheme: $[\mathrm{O} 2 \mathrm{~A}] \rightarrow[$ Pro-OL] $\rightarrow$ [pre-GalC] $\rightarrow$ [immature OL] $\rightarrow$ [mature OL] $\rightarrow$ [myelination].

The galactosphingolipids GalC and sulfatide together comprise $27 \%$ of total myelin lipid, leading to the prediction that these lipids play an important role in OL and myelin biology. Because GalC and sulfatide synthesis begins as OLs enter terminal differentiation, before myelin wrapping per se, we have proposed previously that GalC and/or sulfatide, in addition to their eventual roles as structural components of myelin, are involved in the regulation of OL differentiation (Bansal et al., 1988). Consistent with this hypothesis, both perturbation with specific anti-galactolipid antibodies and inhibition of galactolipid synthesis alter OL differentiation and the maintenance of myelin-like membranes (Bansal et al., 1988; Bansal and Pfeiffer, 1989, 1994a,b). Specifically, exposure of OL progenitors to the anti-GalC/sulfatide monoclonal antibody $\mathrm{R}-\mathrm{mAb}$ results in the reversible inhibition of the onset of terminal differentiation at the pre-GalC-immature OL interface (Bansal and Pfeiffer, 1989). These data and additional data presented in this report [using anti-sulfatide (O4) and anti-galactocerebroside (O1) antibodies] suggest that these anti-galactolipid antibodies mimic a lipid-binding ligand and 
initiate a constitutive inhibitory signal across the plasma membrane via interaction with GalC and/or sulfatide.

A direct approach to analyzing the function of glycolipids in OL differentiation is offered by the generation of mice lacking the GalC-generating enzyme UDP-galactose ceramide galactosyltransferase (CGT-KO) (for review, see Stoffel and Bosio, 1997; Coetzee et al., 1998). These mice lack GalC and sulfatide but have somewhat elevated levels of glucocerebroside. Their abnormalities in myelin structure and function (Bosio et al., 1996; Coetzee et al., 1996; Dupree et al., 1998) indicate the importance of these lipids as structural components of myelin. However, the present work shows that the absence of GalC and sulfatide also leads to enhanced OL differentiation both in culture and in vivo, presumably via alterations of developmental regulation. On the basis of these and previous data (above; Discussion), we propose that GalC and/or sulfatide act as negative regulators of the entry of OLs into terminal differentiation, prior to their role in myelin formation and maintenance.

A preliminary report of these data has been presented (Bansal et al., 1997).

\section{MATERIALS AND METHODS}

\section{Cell culture}

Rat brain. Developmentally synchronized purified populations of cells were prepared at three stages of the OL lineage: early progenitors $(\mathrm{O} 2 \mathrm{~A})$, late progenitors (Pro-OLs), and OLs in terminal differentiation (mature OLs) as described in Bansal et al. (1996). The purity and phenotype of each population were extensively characterized by immunolabeling cells with a panel of antibodies (Bansal et al., 1996).

Mouse brain. Mixed primary cultures of neonatal [postnatal day 1 (P1)-P2] mouse telencephala were prepared by plating dissociated cells in $10 \%$ fetal calf serum in DMEM (FCS/DME) at a density of $2.5 \times 10^{5}$ cells $/ \mathrm{cm}^{2}$ into polylysine-coated $(50 \mu \mathrm{g} / \mathrm{ml}$; Sigma, St. Louis, MO) 35 $\mathrm{mm}$ tissue culture plates for protein isolation and in four-well plates for immunofluorescence microscopy. After $1 \mathrm{~d}$ the cultures were changed to $\mathrm{mN} 2$ (below) plus $1 \% \mathrm{FCS}$ and $1 \%$ horse serum. Isolated OL progenitor cultures were prepared from 9-d-old mixed primary mouse cultures. Several minor but essential variations in the method were used to isolate OL progenitors from mouse, as opposed to rat, cultures. Mixed primary cultures grown in tissue culture flasks were maintained in $10 \% \mathrm{FCS} /$ DME before being shaken overnight (McCarthy and DeVellis, 1980) at $340 \mathrm{rpm}$ (Duchala et al., 1995) (5\% FCS and a shake speed of $200 \mathrm{rpm}$ are used for rat cultures). The cells dislodged after the "shake" were passed through a nylon mesh $(62 \mu \mathrm{m})$ to remove any released sheets of monolayers (not necessary for rat cultures) and further enriched by differential adhesion on tissue culture dishes (more effective than the Petri dishes used for rat cultures) to eliminate astrocytes and macrophages (Bansal and Pfeiffer, 1992). Because "shaken-off" mouse OL progenitors have a much greater tendency to form clumps than do rat OLs, they were triturated to single cells by passing through a flamed Pasteur pipette, suspended in $4 \%$ DNase and $10 \%$ FCS/DME as an additional deterrent to clumping. For immunofluorescence microscopy the cells were plated at a density of $1 \times 10^{4}$ cells $/ \mathrm{cm}^{2}$ into poly-D,Lornithine-coated $(50 \mu \mathrm{g} / \mathrm{ml}$; Sigma) four-well plates in an area of $\sim 1$ $\mathrm{cm}^{2}$ in the middle of the well in $50 \mu \mathrm{l}$. After allowing cell attachment for $30 \mathrm{~min}$, the wells were flooded with media (10\% FCS/DME). After 2-3 $\mathrm{hr}$ the cells were changed to a serum-free, defined medium [mN2 (Gard and Pfeiffer, 1989)] containing DME with D-glucose (4.5 gm/1), human transferrin $(50 \mu \mathrm{g} / \mathrm{ml})$, bovine pancreatic insulin $(5 \mu \mathrm{g} / \mathrm{ml})$, 3,3,5-triiodo-L-thyronine $(15 \mathrm{nM})$, sodium selenium $(30 \mathrm{~nm})$, D-biotin $(10 \mathrm{nM})$, hydrocortisone $(10 \mathrm{nM})$, sodium pyruvate $(0.11 \mathrm{mg} / \mathrm{ml})$, penicillinstreptomycin $(10 \mathrm{IU} / \mathrm{ml}$ and $100 \mu \mathrm{g} / \mathrm{ml}$, respectively), and $0.1 \%$ BSA (all ingredients from Sigma).

Comparison of the phenotypic characterization of OL-lineage cells from isolated mouse and rat cultures. Mouse OL progenitors were isolated from mixed primary cultures and grown in serum-free defined media for up to $6-8 \mathrm{~d}$, a time during which progenitors normally differentiate into OLs in the rat. Whereas mouse OL progenitors in culture exhibited similarities with those of the rat, we observed several significant differences between these two groups. In the rat, A2B5 and GD3 monoclonal antibodies (both recognizing gangliosides) are considered specific markers for OL progenitors, but not astrocytes, in culture. However, in agreement with previous reports (Duchala et al., 1995; Fanarraga et al., 1995; Bambrick et al., 1996), these antibodies labeled both mouse OL progenitors and astrocytes and could not be used as specific progenitor markers for mouse cultures. Unlike rat, mouse cultures also contained a population $(\sim 20 \%$ of total cells $)$ not identified by common markers of OL progenitors (e.g., A2B5, GD3, NG2, and O4), mature OLs (e.g., $\mathrm{GalC}, \mathrm{O}$, and MBP), astrocytes [glial fibrillary acidic protein (GFAP)], or macrophages (OX42). These cells had a broad, rod-like morphology distinct from OL-lineage cells or astrocytes and were present in control and CGT-KO cultures in similar proportions. It is possible that these cells represent fibroblast-like cells reported by Fanarraga et al. (1995). The proportion of astrocytes in control and CGT-KO mouse cultures was similar and comparable with those in rat cultures (i.e., $\sim 2 \%$ up to day 3 and increasing to $\sim 13 \%$ by day 8 ) (Bansal et al., 1996). By $2-3 \mathrm{~d}$ after plating, in rat cultures $98 \%$ of total cells plated (early progenitors) differentiate into Pro-OLs $\left(\mathrm{O}_{4}^{+}\right)$, whereas in mouse cultures, only $70-$ $80 \%$ of total cells become Pro-OLs $(\sim 20 \%$ being the unidentified population). In the rat, $80-90 \%$ of the $\mathrm{O}^{+}$Pro-OLs differentiate into $\mathrm{CNP}^{+} / \mathrm{MBP}^{+} \mathrm{OLs}$; in the mouse cultures only $35 \%$ of $\mathrm{O}^{+}$Pro-OLs acquire CNP and $20 \%$ acquire MBP by $5 \mathrm{~d}$ in the same culture conditions. Thus, although mouse early progenitors differentiated normally into Pro-OLs by $2 \mathrm{~d}$ after plating in $\mathrm{mN} 2$, the proportion of Pro-OLs that differentiated in OLs is much lower in mouse than in rat.

CGT-KO mice. CGT-KO mice were identified by PCR. Genomic DNA was isolated from newborn pup liver (Laird et al., 1991). Two sets of primers were used to identify the wild-type, homozygote, and heterozygote genotype of the pups in the litter: (1) 5'-CTCTCAGAAGGCAGAGACATTGCC-3', (2) 5'-CATCCATAGGCTGGACC-CATGAAC-3', (3) 5'GGAGAGGCTATTCGGCTATGAC-3', and (4) 5'-CGCATTGCATCAGCC-ATGATGG-3'). A 558 bp product corresponding to the wild-type gene was amplified using primers 1 and 2 (Coetzee et al., 1996), and a $315 \mathrm{bp}$ product corresponding to the homozygote and heterozygote mice was amplified using primers 3 and 4. PCR was performed (Gen Amp PCR kit; Perkin-Elmer, Branchberg, NJ) using 30 cycles $\left(2 \mathrm{~min}\right.$ at $94^{\circ} \mathrm{C}, 30 \mathrm{sec}$ at $94^{\circ} \mathrm{C}, 30 \mathrm{sec}$ at $60^{\circ} \mathrm{C}$, and $30 \mathrm{sec}$ at $72^{\circ} \mathrm{C}$ ) followed by $10 \mathrm{~min}$ at $72^{\circ} \mathrm{C}$. Products were separated on $1.6 \%$ agarose gels, and band positions were aligned with control cDNA and molecular weight markers.

Three groups of mice were analyzed: homozygous mutants (referred to as CGT-KO), heterozygous mutants $(+/-)$, and normal wild types $(+/+)$. Dissociated cells from individual telencephala were plated separately into tissue culture dishes or $25 \mathrm{~cm}^{2}$ flasks from each pup in the litter to keep the three groups separate. Wild type and heterozygote mutants were analyzed independently, but no major differences were observed between these two groups, in agreement with previous data (Coetzee et al., 1996; Bosio et al., 1996). Therefore, the data from these two groups were combined in some cases and referred to as control.

\section{Antibody perturbation experiments}

The hybridoma cells producing $\mathrm{O} 4$ or $\mathrm{O} 1$ monoclonal antibodies were grown in heat-inactivated FCS/DME, concentrated from the hybridoma culture supernatants by ammonium sulfate precipitation and dialysis, and characterized as described (Bansal et al., 1988). Supernatant from a nonantibody-producing parent cell line grown and concentrated similarly was used as a control. Antibody concentrations used for perturbation studies were chosen that gave bright immunofluorescence staining (1:25, corresponding to $\sim 6 \mu \mathrm{g}$ of IgM per $\mathrm{ml}$ ) that brought the final concentration of serum components in each group to an equivalent of $6 \%$ by volume. Isolated rat OL progenitors $\left(98 \% \mathrm{~A} 2 \mathrm{~B} 5^{+} / \mathrm{GalC}^{-}\right)$were plated in $\mathrm{mN} 2$ media at a low density $\left(1.5 \times 10^{4}\right.$ cells $\left./ \mathrm{cm}^{2}\right)$ to ensure that the cells remained well spread out on the dish. This is important because cells tend to aggregate at high densities in isolated progenitor or in mixed primary cultures as a result of antibody treatment, leading to secondary effects (Bansal et al., 1988). Progenitors were grown in either control or antibody-containing media for up to $8 \mathrm{~d}$ after plating, with a change of culture medium every $2 \mathrm{~d}$ for the duration of antibody treatment. To test for the reversibility of the $\mathrm{O} 4$ effect, we removed the antibody in one set of cultures after $4 \mathrm{~d}$ of $\mathrm{O} 4$ exposure and grew the cells in control media for 4 additional days.

\section{Immunofluorescence microscopy}

Cells were incubated with HEPES-buffered Earle's balanced salt solution (EBSS-HEPES) containing 3\% normal goat serum (also used for 
diluting antibodies) to block nonspecific absorption and were immunolabeled $\left(15 \mathrm{~min}\right.$ at $4^{\circ} \mathrm{C}$; live staining without fixation is important to retain the specificity of these antibodies) for the plasma membrane surface antigens POA and sulfatide $(\mathrm{O} 4 \mathrm{mAb} ; 1: 50)$ (Sommer and Schachner, 1981; Bansal et al., 1989, 1992), sulfatide (Sulph-1 mAb; 1:50) (Fredman et al., 1988), GalC (O1 mAb; 1:50) (Sommer and Schachner, 1981; Bansal et al., 1989), GalC and sulfatide (R-mAb; 1:25) (Ranscht et al., 1987; Bansal et al., 1989), PLP (O10 mAb; 1:50) (Jung et al., 1996), gangliosides (A2B5 mAb; 1:25) (Eisenbarth et al., 1979), proteoglycan NG2 (anti-NG2 mAb; 1:100; Dr. W. B. Stallcup, La Jolla, CA), and MAG (anti-MAG polyclonal; 1:50; Dr. J. Roder, Montreal, Quebec, Canada). For double-labeling with $\mathrm{O} 4$ and $\mathrm{O} 1$ (both $\mathrm{IgMs}$ ), O1 was biotinylated and applied together with $\mathrm{O} 4$. OLs were double-labeled for internal antigens, with polyclonal anti-MBP and monoclonal anti-CNP (1:100 diluted in 3\% BSA and $0.5 \mathrm{M}$ Tris-HCl, pH 7.6; Sternberger Monoclonals, Baltimore, MD) after fixation (4\% $p$-formaldehyde; 20 min), detergent treatment (0.05\% saponin; $5 \mathrm{~min})$, and blocking in $3 \%$ BSA and Tris at room temperature $\left(30 \mathrm{~min}\right.$ or overnight at $\left.4^{\circ} \mathrm{C}\right)$. Astrocytes were labeled for GFAP (anti-GFAP mAb; 1:100; Virginia Lee, University of Pennsylvania) after fixation with methanol at $-20^{\circ} \mathrm{C}$ for $2 \mathrm{~min}$. Cells were then incubated with a combination of two secondary antibodies for $20 \mathrm{~min}$ : FITC-conjugated goat anti-mouse IgM (1:50; $\mu$-chain specific, for O4, O1, O10, and A2B5; Chemicon, Temecula, CA) plus either tetramethylrhodamine isothiocyanate (TRITC)-conjugated avidin (1:100; for biotinylated O1; Vector Laboratories, Burlingame, CA), TRITC-conjugated goat anti-rat $\operatorname{IgG}$ (1:50; for GFAP; Chemicon), cy3-conjugated goat anti-mouse $\operatorname{IgG}(1: 600 ; \gamma$-chain specific, for CNP, $\mathrm{R}-\mathrm{mAb}$, and Sulph-1; Jackson ImmunoResearch, West Grove, PA), or cy3-conjugated donkey anti-rabbit IgG (1:600; for MAG and MBP; Jackson ImmunoResearch). Cells were mounted in $50 \%$ glycerol, $\mathrm{pH}$ 8.6, and $2.5 \%$ diazobicyclo- $(2,2,2)$ octane to suppress fading and examined by epifluorescence microscopy. Total cell number was determined by counting cells labeled with a nuclear counterstain $(1 \mu \mathrm{g} / \mathrm{ml}$ Hoechst dye 33342; Sigma) included with the secondary antibodies. Washing between steps was performed with three 5 min changes of $1 \%$ NGS and EBSS-HEPES or of Tris for MBP. The use of 3\% BSA and Tris for MBP staining reduced the background.

To identify cells that were in the S phase of the cell cycle, we exposed cells to bromodeoxyuridine (BrdU) at a final concentration of $50 \mu \mathrm{M}$ for $24 \mathrm{hr}$ at $37^{\circ} \mathrm{C}$ for incorporation into newly synthesized DNA. The cells were fixed with ethanol/glacial acetic acid $(95: 5)$ at $-20^{\circ} \mathrm{C}(2 \mathrm{~min})$, denatured with $2 \mathrm{~N} \mathrm{HCl}(10 \mathrm{~min})$, neutralized with $0.1 \mathrm{~m}$ sodium borate, pH 8.5 (10 min), and incubated with anti-BrdU (1:50; 20 min; Becton Dickinson, Lincoln Park, NJ) followed by goat anti-mouse IgG conjugated to cy3 (Jackson ImmunoResearch).

\section{In situ hybridization}

Postnatal day 7 rat pups were anesthetized and perfused through the heart with $4 \%$ paraformaldehyde (PF). Brains were removed and postfixed for $2 \mathrm{~d}$ in $3 \% \mathrm{PF}$ at $4^{\circ} \mathrm{C}$, transferred to 10 and $30 \%$ sucrose in PBS sequentially for $24 \mathrm{hr}$ each, and frozen in OCT. The whole brain was sagittally sectioned at $10 \mu \mathrm{m}$ thickness on a cryostat (Alert Scientific). Hybridization was performed as described in Fuss et al. (1997). Briefly the sections were thaw-mounted onto RNase-free Superfrost-Plus microscope slides (Fisher Scientific, Pittsburgh, PA) and fixed in 3\% PF in PBS for $30 \mathrm{~min}$. The sections were treated with $0.1 \mathrm{M} \mathrm{HCl}(5 \mathrm{~min})$ followed by acetylation with $0.1 \mathrm{M}$ triethanolamine, $\mathrm{pH} 8$, containing acetic anhydride (10 min), washed in $2 \times$ SSC, and air dried. Hybridization was performed overnight using digoxigenin-labeled sense and antisense cRNA probes in the presence of $50 \%$ formamide at $50^{\circ} \mathrm{C}$ (probe specific for PLP covering the entire coding region was a gift from Drs. B. Fuss and W. B. Macklin, Cleveland, OH). After RNase treatment (RNase A, $20 \mu \mathrm{g} / \mathrm{ml}$; RNase T1, 1 unit; $\left.37^{\circ} \mathrm{C} ; 30 \mathrm{~min}\right)$, the sections were washed in $0.2 \times \mathrm{SSC}$ at $50^{\circ} \mathrm{C}(5$ $\mathrm{min})$ and at room temperature $(5 \mathrm{~min})$. After equilibration in $100 \mathrm{~mm}$ Tris-HCl plus $150 \mathrm{~mm} \mathrm{NaCl}(10 \mathrm{~min})$ and blocking nonspecific binding in $1 \%$ blocking buffer (Boehringer Mannheim, Indianapolis, IN) and $0.5 \%$ BSA (30 min; room temperature), the bound cRNA was detected using an alkaline phosphatase-coupled anti-digoxigenin antibody (1:500; $2 \mathrm{hr}$; Boehringer Mannheim). After equilibration in $100 \mathrm{~mm}$ Tris- $\mathrm{HCl}, \mathrm{pH} 9.5$, $100 \mathrm{~mm} \mathrm{NaCl}$, and $50 \mathrm{mM} \mathrm{MgCl}_{2}$, color development in the presence of 4-nitroblue tetrazolium chloride, 5-bromo-4-chloro-3-indolylphosphate, and levamisole was performed in the dark at room temperature. The sections were then incubated in either Hoechst dye $33342(1 \mu \mathrm{g} / \mathrm{ml}$; Sigma) or propidium iodide $(5 \mu \mathrm{g} / \mathrm{ml})$ to counterstain the nucleae, air-dried, and mounted with $90 \%$ glycerol. Analysis and cell counting were performed as follows: twenty-six pups were analyzed ( $9 \mathrm{KO}$ and 16 controls) from eight liters. Comparisons between mutants and controls were made within the same litters. Two to four $10 \mu \mathrm{m}$ sections from each animal, cut sagittally from midline to laterally, were analyzed. Control and CGT-KO sections were matched so that they were equidistant from the midline. The total number of PLP mRNA ${ }^{+}$cells present in the whole corpus callosum and cerebral cortical area of the brain section was counted systematically using a grid and $20 \times$ objective.

\section{$R N A$ isolation and Northern blotting}

Total cellular RNA was isolated by guanidinium thiocyanate-phenolchloroform extraction (Chomczynski and Sacchi, 1987). For Northern blots (Ausubel et al., 1991), radioactive probes were prepared by random priming (Prime-it II; Stratagene, La Jolla, CA), purified on NucTrap push-columns (Stratagene), and hybridized in the presence of salmon sperm DNA. Membranes were washed $(2 \times$ SSC and $0.1 \%$ SDS; 5 min; room temperature; $2 \times \mathrm{SSC}$ and $1 \% \mathrm{SDS} ; 30 \mathrm{~min} ; 62^{\circ} \mathrm{C}$; and $0.1 \times \mathrm{SSC}$; $30 \mathrm{~min}$; room temperature). Blots were quantified (Packard Instant Imager 2024; Packard Canberra) and exposed $\left(24-72 \mathrm{hr} ;-70^{\circ} \mathrm{C}\right)$ to Kodak X-Omat film with an intensifying screen. Blots were stripped $\left(0.1 \times \mathrm{SSC} ; 1 \% \mathrm{SDS} ; 100^{\circ} \mathrm{C} ; 15 \mathrm{~min}\right)$ and reprobed for glyceraldehyde3-phosphate dehydrogenase (GAPDH) to normalize for RNA loading. The cDNA probe used was a 595 bp PCR product specific to the second exon of CGT (Coetzee et al., 1996); this exon is not homologous to UDP glucuronosyl transferases and detects only CGT mRNA.

\section{Western and immunodot blotting}

MBP was quantified by immunodot blotting and computer-enhanced densitometric scanning; MBP isoforms were visualized by SDS-PAGE and Western blotting (Ausubel et al., 1991; Bansal and Pfeiffer, 1994a, 1997). Briefly, cell pellets in $1 \%$ SDS and $0.5 \%$ deoxycholate were sonicated $\left(30 \mathrm{sec} ; 4^{\circ} \mathrm{C}\right)$ and incubated $(30 \mathrm{~min})$ in $1 \% \mathrm{SDS}$ at $37^{\circ} \mathrm{C}$. Serially diluted samples $(100 \mu \mathrm{l})$ were applied to nitrocellulose filter paper in a 96-well microfiltration apparatus (Schleicher \& Schuell, Keene, $\mathrm{NH}$ ) at $0.03-4 \mu \mathrm{g}$ of protein per well. After $30 \mathrm{~min}$, the filter was removed from the manifold and dried at room temperature for $30 \mathrm{~min}$. Filters immunostained with anti-MBP $(1: 10,000$; overnight incubation; at room temperature), followed by horseradish peroxidase-conjugated anti-rabbit IgG (1:6000; Amersham, Arlington Heights, IL), were developed using the ECL technique (Amersham).

\section{RESULTS}

To examine the role of GalC and sulfatide in the differentiation of OLs, we studied myelinogenesis using two different experimental approaches: (1) perturbation of normal OL differentiation by anti-galactolipid antibodies and (2) analysis of OL development in a mouse unable to synthesize these lipids because of a targeted mutation of the CGT gene (referred to as CGT-KO).

\section{Oligodendrocyte progenitor differentiation is reversibly inhibited by antibodies against galactolipids}

We have shown previously that the monoclonal antibody R-mAb reversibly inhibits OL differentiation at the "pre-GalC" stage (Bansal and Pfeiffer, 1989). Because R-mAb recognizes both GalC and sulfatide (Bansal et al., 1989), we have extended these studies to investigate whether a similar block could be instigated by two other anti-galactolipid antibodies, O4 that recognizes sulfatide but not GalC or O1 that recognizes GalC but not sulfatide (Bansal et al., 1989). Isolated rat OL progenitor cultures were grown in the presence of either $\mathrm{O} 4 \mathrm{mAb}$ or $\mathrm{O} 1 \mathrm{mAb}$ for $8 \mathrm{~d}$ after plating. Control cultures were maintained either in serumfree $\mathrm{mN} 2$ media alone or in $\mathrm{mN} 2$ supplemented with serum components present in the antibody preparations (see Materials and Methods) to control for possible effects of their presence. Entry into terminal differentiation was determined by immunofluorescence microscopy for the differentiation markers O1 (Fig. 1) and MBP (which showed a similar pattern; data not shown). In serum-free medium, progenitors developed into $\mathrm{O}^{+}\left(\mathrm{GalC}^{+}\right)$ OLs on the usual schedule (Fig. 1, open triangles). As expected, 


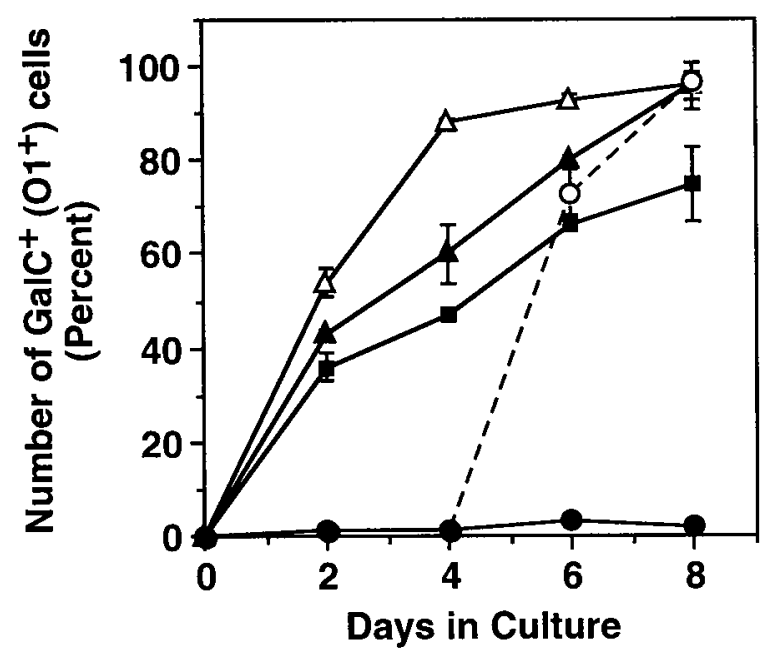

Figure 1. Reversible inhibition of OL differentiation by antibody $\mathrm{O} 4$ analyzed by immunofluorescence microscopy. Isolated rat OL progenitors were grown for $0-8 \mathrm{~d}$ in serum-free defined media alone (open triangles) or with the addition of either $\mathrm{O} 4$ antibody (closed circles), $\mathrm{O} 1$ antibody (closed squares), or control serum components that are present in both antibody solutions (closed triangles). In one group, cells grown in $\mathrm{O} 4$ were transferred to antibody-free media after $4 \mathrm{~d}$ and grown further in the absence of the antibody to test for the reversibility of the inhibition (dashed line, open circles). The percent of total OL-lineage cells that became immunolabeled for $\mathrm{O} 1$ (i.e., $\mathrm{GalC}^{+}$) as they enter terminal differentiation has been plotted as a function of time. A representative experiment is shown. Error bars show the spread of the means. Note that although addition of serum components by themselves slightly retarded terminal differentiation, exposure to $\mathrm{O} 4$ antibody in addition totally inhibited it. Antibody O1, on the other hand, was unable to induce such an arrest.

the presence of serum components alone retarded the differentiation slightly (Fig. 1, closed triangles). However, when OL progenitors were exposed to $\mathrm{O} 4 \mathrm{mAb}$, terminal differentiation was completely blocked at the pre-GalC stage as demonstrated by the absence of the appearance of $\mathrm{O}^{+}$OLs (Fig. 1, closed circles). Characteristic of the pre-GalC stage, the blocked cells had a multipolar, simple, but branched morphology and were $\mathrm{O} 4{ }^{+}$ [many of which were also $\mathrm{R}-\mathrm{mAb}^{+}$but $\mathrm{O}^{-}{ }^{-}$(Bansal and Pfeiffer, 1992)]. Total cell counts were unaffected by $\mathrm{O} 4$ treatment, and the cells remained viable. Although the cells were unable to enter terminal differentiation, they were not actively proliferating, indicated by the low rate of BrdU incorporation (e.g., at $4 \mathrm{~d}, 1.6$ and $1.4 \% \mathrm{BrdU}^{+}$cells were present in O4-treated and control cells, respectively). The capacity of cells blocked by $\mathrm{O} 4$ to reinitiate differentiation was tested by replacing the O4-containing media with control media after $4 \mathrm{~d}$ of antibody treatment. These cells readily differentiated into $\mathrm{O} 1^{+} \mathrm{OLs}$ and reached levels comparable with controls within $2 \mathrm{~d}$ (Fig. 1, dashed line, open circles). As for R-mAb, O4 induced only a partial inhibition in the absence of serum components (data not shown), suggesting that molecules present in serum participate with $\mathrm{O} 4$ to induce inhibition of differentiation. In contrast to $\mathrm{O} 4$, monoclonal antibody $\mathrm{O} 1$ that recognizes GalC but not sulfatide produced only a slight inhibition over that induced by serum components alone (Fig. 1, squares).

O4 recognizes POA on Pro-OLs (which do not synthesize sulfatide), as well as sulfatide on OLs (Bansal et al., 1992) (see below). The block of differentiation is apparently caused by the interaction of $\mathrm{O} 4$ with sulfatide because $\mathrm{R}-\mathrm{mAb}$ (which recognizes sulfatide but not POA) instigates a similar inhibition (Ban-

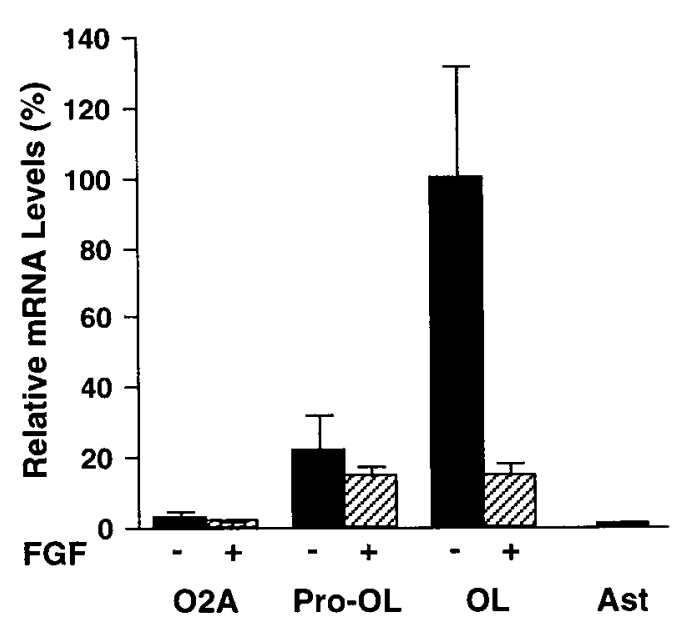

Figure 2. Developmental expression of CGT mRNA during OL-lineage progression. Northern blot analysis of mRNA from purified populations of astrocytes (Ast; negative control), rat early progenitors $(O 2 A)$, late progenitors (Pro-OL), and mature OLs $(O L)$ grown for $2 \mathrm{~d}$ in the absence $(-)$ or presence $(+)$ of FGF is shown. Total RNA $(20 \mu \mathrm{g} /$ lane $)$ was loaded, and the blots were first hybridized with a cDNA probe for CGT and then rehybridized with a probe for GAPDH. The mRNA levels were quantified and normalized for RNA loading (GAPDH), and values were expressed as relative mRNA levels; the highest level was set at $100 \%$. Error bars represent SEM $(n=3-6)$. Note that CGT mRNA is first expressed at the Pro-OL stage in the OL lineage.

sal and Pfeiffer, 1989, 1992). We conclude that O4 mAb inhibits entry into terminal differentiation, that this inhibition is fully reversible, and that interactions with sulfatide rather than with GalC or POA may be involved in the inhibitory phenomenon.

To test further the proposed inhibitory role of these galactolipids on the differentiation of OLs, we next analyzed the functional impact of the elimination of these lipids in a mouse unable to synthesize them because of a targeted mutation of the CGT gene. We first examined the developmental expression pattern of CGT.

\section{CGT mRNA is first expressed at the Pro-OL stage, before the synthesis of galactocerebroside and sulfatide by mature OLs}

In addition to the major glycosphingolipids GalC and sulfatide, CGT also catalyzes the synthesis of a number of other glycolipids during OL development (e.g., monogalactosyldiglyceride, its sulfated form seminolipid, and perhaps others) (Singh and Pfeiffer, 1985; Bansal et al., 1992; van der Bijl et al., 1996) that may be important for OL development. Therefore, the possibility was investigated by Northern blotting that CGT may be expressed in the progenitor stages of the OL lineage. Isolated OL-lineage cells from rat telencephalon at three stages of development were analyzed (Fig. 2). CGT mRNA was not detected in early progenitors $\left(\mathrm{O} 2 \mathrm{~A}\right.$; $\left.\mathrm{A} 2 \mathrm{~B} 5^{+} / \mathrm{O}^{-}\right)$, first appeared at the late progenitor stage (Pro-OLs; A2B5 ${ }^{+} / \mathrm{O}^{+} / \mathrm{GalC}^{-}$) at $\sim 20 \%$ of the maximal level, and reached maximal levels as the cells differentiated into mature OLs $\left(\mathrm{GalC}^{+} / \mathrm{MBP}^{+}\right)$. As shown previously (Bansal and Pfeiffer, 1997), the level of CGT mRNA in OLs was dramatically downregulated by fibroblast growth factor (FGF-2), in parallel with other markers of terminal differentiation. CGT mRNA was not detected in astrocytes. The lower level of CGT mRNA detected in Pro-OL cultures was not caused by a small, contaminating population of mature GalC expressing OLs, because immunofluorescence analysis showed that these cultures had only 

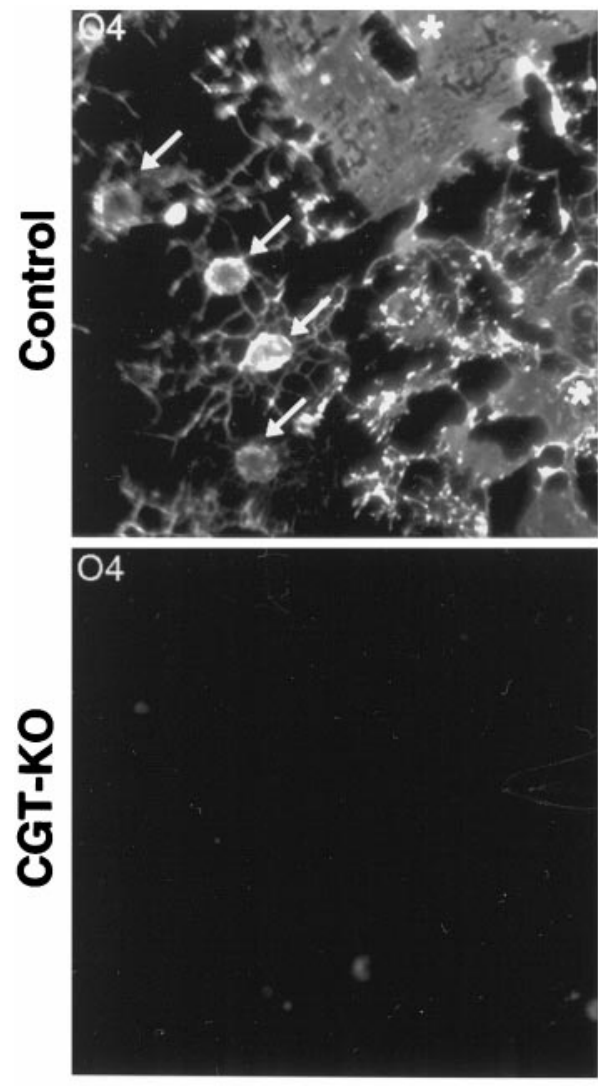
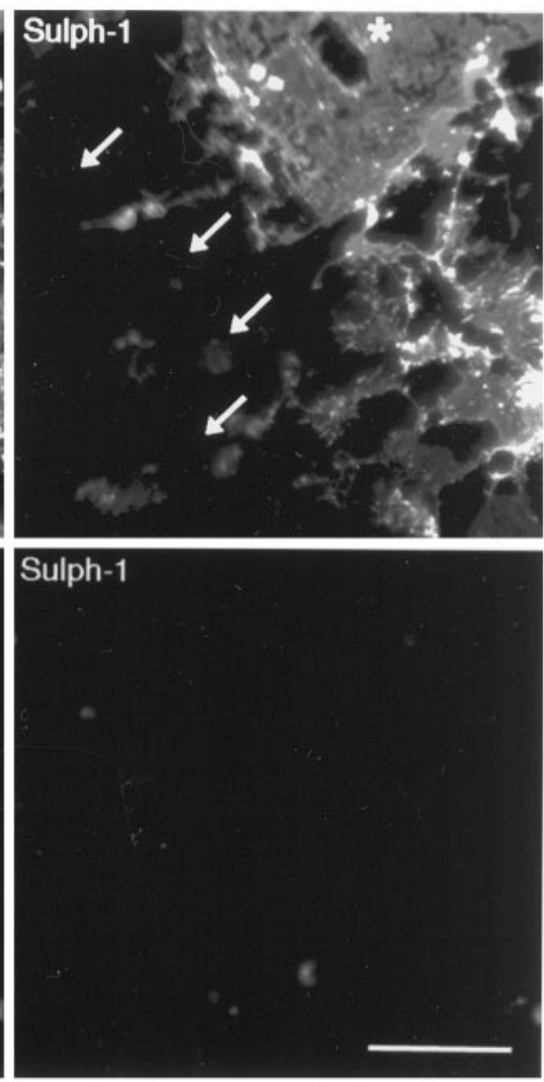

Figure 3. CGT-KO mice do not express POA, a marker of the Pro-OL stage (identified by $\mathrm{O} 4$ antibody). Parallel mixed primary cultures from control and CGT-KO were double-stained with antibodies O4 and Sulph-1 at a time in culture when both Pro-OLs and OLs are present. In the control cultures both Pro-OLs (arrows; expressing POA) and OLs (star; expressing sulfatide) were stained by $\mathrm{O} 4$, whereas only OLs (star) were labeled by Sulph-1. In the CGT-KO cultures, both OLs and Pro-OLs remain unstained by O4 as well as by Sulph-1, showing that not only sulfatide but also POA was absent, suggesting that CGT activity is required for the synthesis of POA. Scale bar, $50 \mu \mathrm{m}$. negligible levels of differentiated OLs (see Bansal et al., 1996). We conclude that CGT mRNA is produced as early as the Pro-OL stage, before the synthesis of GalC and sulfatide. One marker of the Pro-OL stage in particular, POA, was therefore investigated next.

\section{Expression of proligodendroblast antigen requires CGT activity, as shown by the loss of 04 expression by Pro- OLs in the CGT-KO mice}

We have shown previously that mAb O4 first recognizes the Pro-OL marker POA [an unidentified molecule referred to as proligodendroblast antigen (Bansal et al., 1992)] and subsequently, as differentiation proceeds, sulfatide on mature OLs. In contrast, the monoclonal antibody Sulph-1 (Fredman et al., 1988) recognizes sulfatide but not POA. By double-labeling cultures with these antibodies (at a developmental stage when both ProOLs and mature OLs were present), we examined whether or not POA expression is associated with CGT expression (Fig. 3). As expected, in control cultures, O4 labeled both Pro-OLs and mature Ols, whereas Sulph-1 labeled only mature OLs. In contrast, in CGT-KO cultures, both O4 and Sulph-1 labeling was absent. The absence of POA expression suggests that it is a lipid and its synthesis requires CGT activity during the Pro-OL stage. Consequently, the CGT mutation could in principle affect the physiology of not only mature OLs but also of Pro-OLs. To investigate this, we next examined the differentiation of OLs to gain further insight into the role of these lipids in OL development.

\section{The phenotype and morphology in culture of mature OLs lacking ceramide galactosyltransferase is similar to that of control cells}

The effect of eliminating CGT on the morphology and phenotype of mature OLs derived from CGT-KO mice was first examined in culture by immunofluorescence microscopy. As expected for cells without CGT activity, these cells did not express galactocerebroside $\left(\mathrm{O} 1^{-}\right)$(Fig. 4) or sulfatide $\left(\mathrm{O}^{-}{ }^{-}\right.$, Sulph-1 $\left.{ }^{-}\right)$(Fig. 3). However, they expressed the myelin markers MBP (see Figs. 4, 6, 7), PLP $\left(\mathrm{O}^{+}{ }^{+}\right.$) (Fig. 5), CNP (Fig. 6A), and MAG (data not shown) in a similar manner as control OLs. CGT-KO OLs made extensive membranes that were comparable in both scope and design with that in control cells in both enriched OL cultures (Figs. 4, 6) and mixed primary cultures (Fig. 7). We conclude that for mature OLs in culture, the absence of GalC and sulfatide from the OL plasma membrane does not lead to major disruptions in the synthesis and incorporation of major myelin proteins or to a disorganization of the cytoarchitecture.

\section{PLP transport to the OL plasma membrane proceeds in the absence of galactolipids}

Inhibition of the synthesis of glycosphingolipids has been reported to disrupt the transport of PLP to myelin membrane, leading to a suggestion that glycolipids (probably sulfatide) are coupled to the intracellular transport of PLP to the plasma membrane surface (Pasquini et al., 1989; Brown et al., 1993). Our present approach of analysis has allowed us to test this hypothesis more directly. To determine whether PLP could reach the plasma membrane surface in the absence of these glycolipids, unfixed, nonpermeabilized OLs from CGT-KO cultures were immunolabeled with a mAb that recognizes an extracellular domain of PLP [O10 (Jung et al., 1996)]. CGT-KO OLs were immunolabeled for PLP on their surfaces (Fig. 5). We conclude that the lack of sulfatide in the CGT-KO did not deter PLP transport to the cell surface. These data do not preclude the possibility that sulfatide and PLP are normally cotransported in a noncompulsory manner. 
Figure 4. Phenotype and morphology of mature OLs in CGT-KO cultures. Double-immunolabeling with anti-MBP and anti-GalC is shown. CGT-KO OLs express MBP, but not GalC, and produce extensive membranous sheaths comparable with control mouse OLs in culture. A single, typical OL (arrow) covering the entire $40 \times$ field is shown. Scale bar, $50 \mu \mathrm{m}$.

Figure 5. Analysis of PLP expression on the plasma membrane of CGT-KO OLs. Purified OL cultures from CGT-KO mice were doubleimmunolabeled with MBP and anti-PLP (O10) without previous fixation. PLP expression by CGT-KO OLs suggests that PLP was transported to the OL plasma membrane surface in the absence of sulfatide and GalC. Scale bar, $50 \mu \mathrm{m}$.
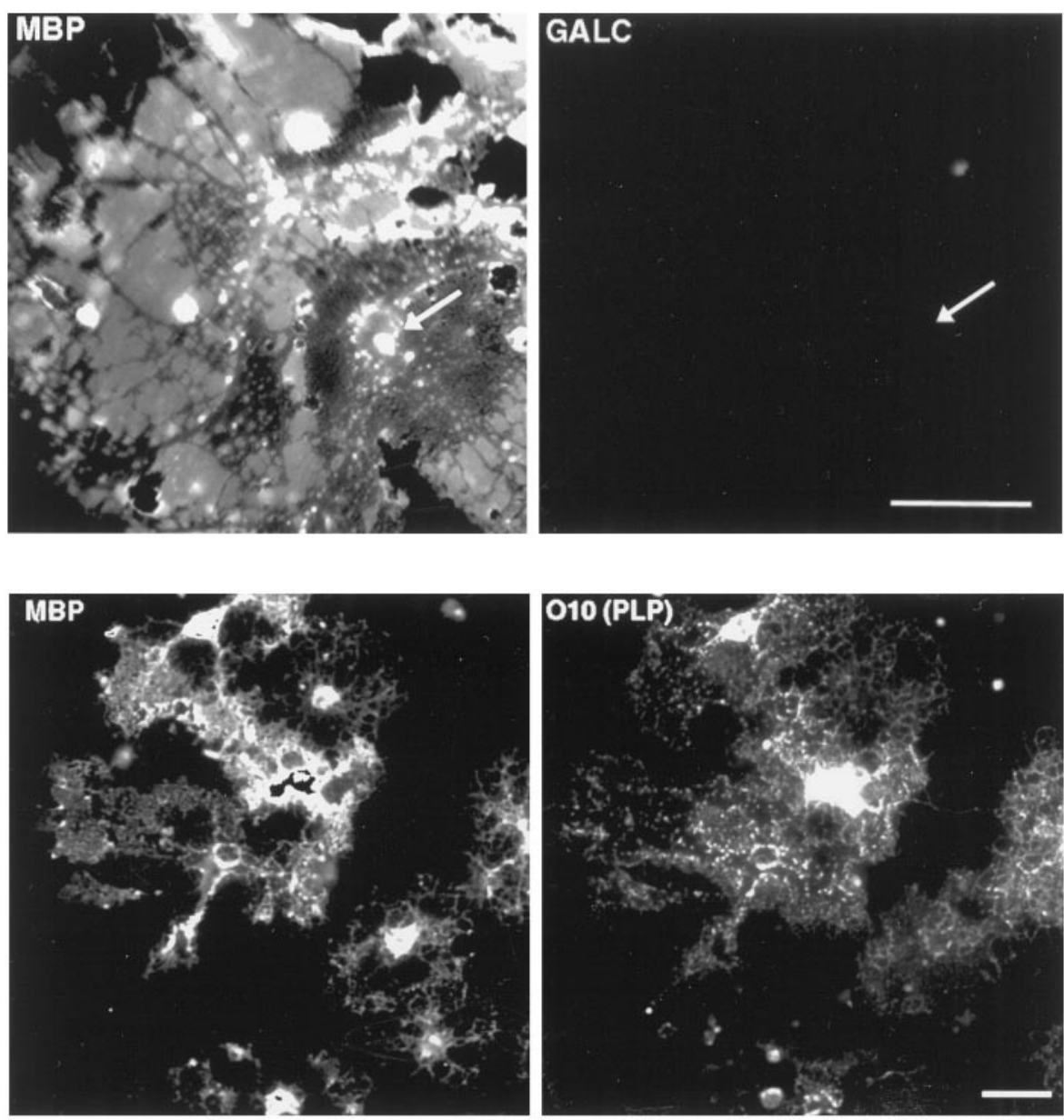

\section{Oligodendrocyte differentiation is enhanced in purified progenitor cultures from CGT-KO mice with respect to both rate and extent}

We next examined the effects of the CGT mutation on the timing and extent of differentiation in the culture of progenitors to mature OLs. Purified populations of progenitors from parallel control and CGT-KO cultures were analyzed as a function of time by immunofluorescence microscopy (Fig. 6). The general pattern of the OL developmental time course from the two groups was similar, as shown, for example, by the maintenance of the normal lag between the expression of CNP and MBP by the cells. However, in CGT-KO cultures, the number of both $\mathrm{CNP}^{+}$and $\mathrm{MBP}^{+}$cells was increased approximately twofold compared with that in control cultures. This was true when the data were expressed either as percents (Fig. $6 \mathrm{~A}$ ) or as cell numbers per $40 \times$ field. For example, at day 4 in culture there were $4.9 \pm 0.6$ and $10.4 \pm 1.1 \mathrm{MBP}^{+}$cells in the control and CGT-KO populations, respectively, whereas the total number of cells was comparable in the two groups (i.e., $35 \pm 4.8$ and $36 \pm 2.8$, respectively). In addition, the rate of differentiation was faster in the mutant cultures. That is, in addition to an increased number of $\mathrm{CNP}^{+}$ cells, as early as the second day after plating the majority of mutant $\mathrm{CNP}^{+}$cells exhibited a more complex, mature OL morphology with intense CNP staining, compared with the relatively weakly stained, morphologically immature OLs in control cells. For example, the number of mature $\mathrm{CNP}^{+} \mathrm{OLs}$ (i.e., intensely stained, morphologically mature cells) present in CGT-KO versus control cultures was 6 -fold more at $2 \mathrm{~d}, 2.6$-fold more at $3 \mathrm{~d}$, and 2.1-fold more at $4 \mathrm{~d}$. With time, although the majority of OLs in control cultures became morphologically indistinguishable from CGT-KO OLs, they remained fewer in number at least up to $5 \mathrm{~d}$, the last time studied (Fig. 6A). We conclude that CGT-KO OLs matured faster and in higher numbers than did their control counterparts when grown as purified cell cultures.

\section{The difference between the differentiation potential of control and CGT-KO oligodendrocyte progenitors is more pronounced in mixed primary cultures}

It is routinely observed that in normal control mixed primary cultures, the rate and extent of OL differentiation are lower than in isolated cultures (e.g., Bansal and Pfeiffer, 1989). Therefore, we predicted that because of the lowering of the control baseline, the difference between the differentiation potential of OLs in control and mutant cultures should be even more pronounced in mixed than in purified cultures (see also Discussion). To test this we examined the differentiation by CGT-KO OLs in mixed primary cultures (Fig. 7). The expression of MBP was assayed as a marker for OL maturation by immunofluorescence microscopy (Fig. 7A) and Western/dot blot analysis (Fig. $7 B, C$ ) as a function of time. The level of MBP expression was comparable in the wild-type and heterozygous groups (Fig. 7B, solid lines). In contrast, in the CGT-KO cultures there was a 3.5 -fold increase in the level of MBP protein expression compared with that in controls (Fig. 7B, dashed line), an enhancement also reflected in a dramatic increase in the number of mature OLs immunolabeled for MBP (Fig. 7A). The level of MBP expression remained high throughout the 


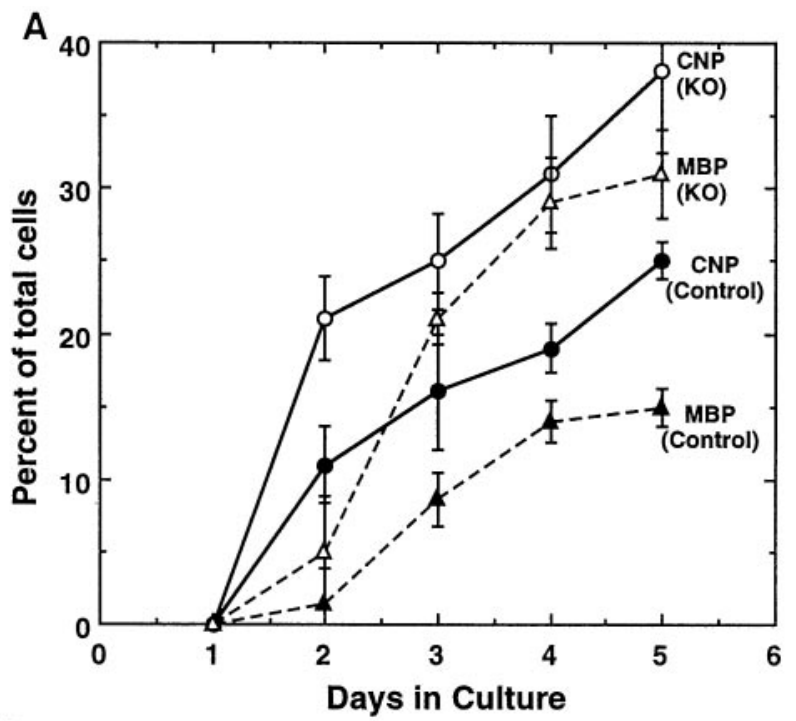

B
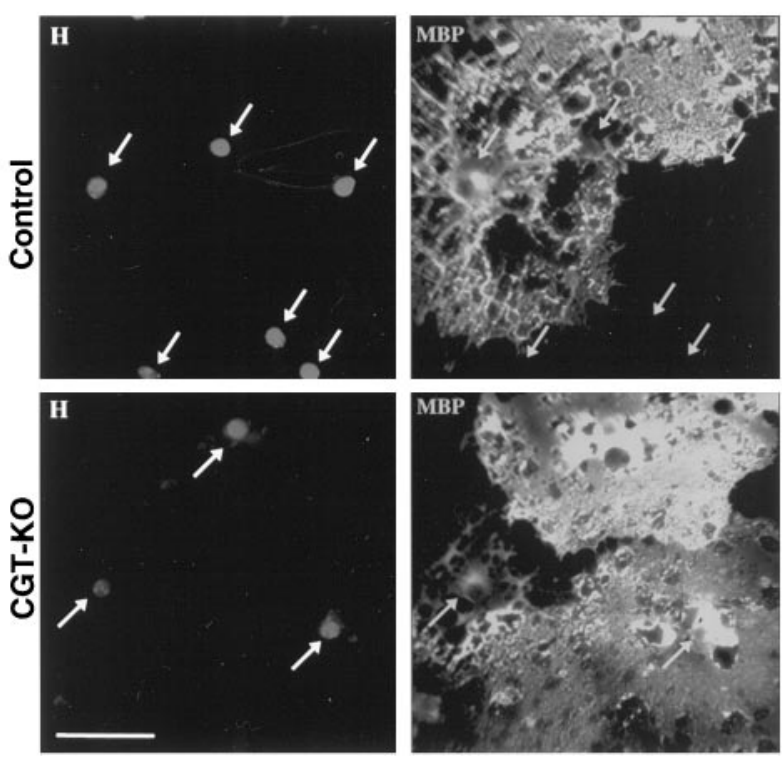

Figure 6. Analysis of OL differentiation in purified progenitor cultures from CGT-KO mice by immunofluorescent microscopy. $A$, Time course of OL differentiation. The percent of total cells immunolabeled at each time point for CNP (solid lines, circles) or MBP (dashed lines, triangles) from the control group (filled circles, filled triangles) or CGT-KO mice (open circles, open triangles) is plotted as a function of time. Both weakly labeled immature OLs and mature OLs are included in the cell counts. At each point 400-600 cells were counted. Error bars represent SEM $(n=3-5)$. Note that cultures of CGT-KO progenitors yield a higher number of differentiated OLs compared with control cultures. $B$, Isolated OLs double-immunolabeled for MBP and a nuclear stain, Hoescht dye $(H)$, after $4 \mathrm{~d}$ in culture. Note that in the fields shown, in the control group only two out of six cells shown in the field (arrows) are differentiated, whereas in the CGT-KO group three out of three cells are differentiated. Scale bar, $50 \mu \mathrm{m}$.

course of the experiment, i.e., $23 \mathrm{~d}$. All observed isoforms of MBP were elevated in CGT-KO OLs (Fig. 7C). Therefore, we conclude that the relative difference between control and CGT-KO in the extent of OL differentiation potential is increased in mixed primary cultures (Fig. 7) compared with purified CGT-KO OL cultures (Fig. 6).
The increase in OL number in CGT-KO mouse cultures is not attributable to better proliferation or survival of Pro-OLs

The increase in the number of mature OLs in CGT-KO cultures could be caused by either (1) a greater efficiency of Pro-OLs for terminal differentiation or (2) an increased number of available Pro-OLs for differentiation to mature OLs. An increase in Pro-OL number could, in turn, be attributable either to an increased proliferation rate and/or an enhanced survival of ProOLs. Experiments were next performed to investigate which of these mechanisms are operative [note that a direct measurement of the number of CGT-KO Pro-OLs was experimentally not feasible, because the loss of POA from these cells precluded the immunoidentification of these cell by $\mathrm{O} 4 \mathrm{mAb}$ (Fig. 3), which is the only definitive marker for this stage of OL development].

To test for proliferation of Pro-OLs, the numbers of cells that incorporated BrdU during a $24 \mathrm{hr}$ exposure were examined at 2 and $3 \mathrm{~d}$ after plating by immunofluorescence microscopy with anti-BrdU (Fig. 8A). The majority of cells in the control culture at $2 \mathrm{~d}$ are at the Pro-OL stage of development (see Materials and Methods). Normally in control cultures grown as described above, $\sim 15 \%$ of cells incorporate BrdU after $2 \mathrm{~d}$ in $\mathrm{N} 2$ media; the number falls to $\sim 5 \%$ by $3 \mathrm{~d}$ as progenitors differentiate (Fig. $8 \mathrm{~A}$, black bars). In the CGT-KO cultures, at both 2 and $3 \mathrm{~d}$, we did not observe increased BrdU incorporation compared with that in control cultures (Fig. 8B, striped bars). Therefore, increased Pro-OL number because of increased proliferation could not have accounted for an increase in mature OL numbers in the mutant cultures. The earlier decline in BrdU incorporation in the CGT-KO compared with controls is consistent with an earlier differentiation of progenitors into postmitotic mature OLs in these cultures (Fig. 6A). The data in Figure $8 A$ are expressed as percents to allow normalization of multiple experiments. However, results expressed as the number of cells for any given experiment led to the same conclusion. For example, at $2 \mathrm{~d}$ in culture the numbers of $\mathrm{BrdU}^{+}$cells per $40 \times$ field in control and CGT-KO cultures were $9.4 \pm 0.9$ and $2.9 \pm 1.4$, respectively, whereas the total number of cells was comparable in the two groups, i.e., $59 \pm 6.6$ and $65 \pm 8.6$ per $40 \times$ field, respectively.

Because the proliferation data indicated that more progenitors are not being produced in CGT-KO compared with control cultures, we next examined whether the survival of CGT-KO progenitors was enhanced relative to control progenitors (Fig. 8B). For mouse, a loss of OL-lineage cells in cultures of purified OL progenitors, grown as described above, is routinely observed with time. To compare the extents of survival between the two groups, total live cell numbers were determined by counting the number of nonpyknotic nucleic (stained with Hoescht dye) as a function of time. Note that at $2 \mathrm{~d}$ the majority of cells are progenitors (see Materials and Methods). The number of cells at this time point was found to be comparable in the two groups (Fig. 8B). This suggests that the survival of CGT-KO progenitors was not better than the controls, and therefore this factor could not contribute to an increase in progenitor number. In addition, this shows that higher numbers of differentiated OLs could not have been artificially attained because of a preferential loss of progenitors in the CGT-KO population.

Therefore, because CGT-KO OL progenitors neither proliferated nor survived more avidly than did their counterparts in control cultures, we conclude that the higher percent of terminally differentiated OLs is attributable not to an increased Pro-OL 
A
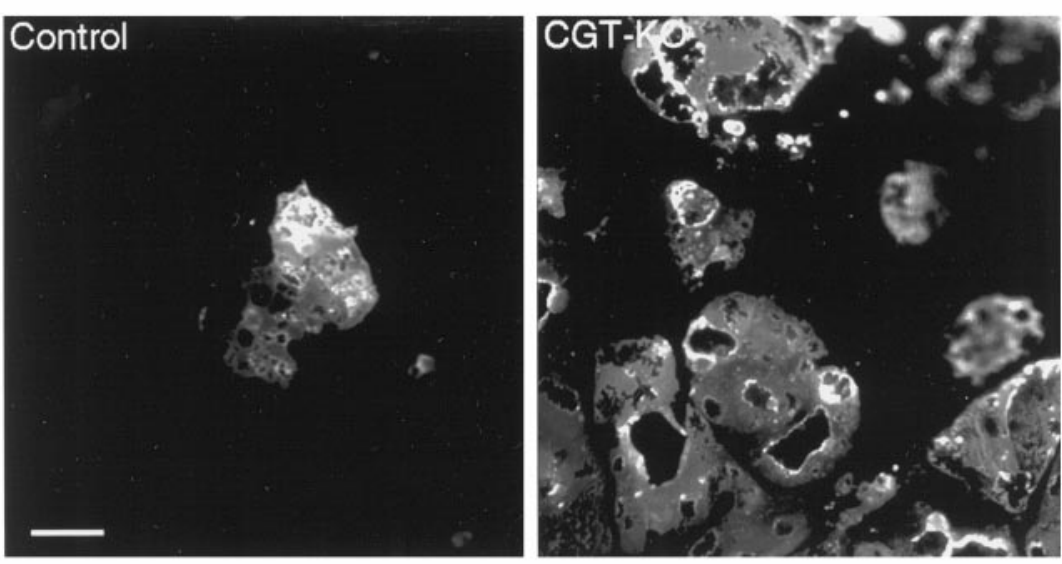

Figure 7. Analysis of OL differentiation in mixed primary cultures from CGT-KO by immunofluorescent microscopy. $A$, Mixed primary cultures of similar age from control and CGT-KO mice immunolabeled for MBP. Although both fields have a similar number of total cells determined by phase contrast (data not shown), note that in the control only one differentiated OL is seen, whereas in the CGT-KO cultures numerous mature OLs are already present. Scale bar, $50 \mu \mathrm{m}$. B. Biochemical analysis of CGT-KO OL differentiation in mixed primary cultures. MBP expression was measured by immunodot blotting followed by densitometric scanning as a function of time in culture. The MBP expression levels were comparable in the wild-type ( filled circles) and heterozygous (filled triangles) groups, whereas the CGT-KO group (open circles, dashed line) showed markedly elevated levels. Error bars represent SEM $(n=2$ for wild type; $n=4$ for heterozygous and $n=4$ for homozygous groups from a litter of 10 pups). One representative experiment out of five is shown. Note that the extent of OL differentiation in mixed primary cultures is even more pronounced than that in the purified OL cultures. $C$, Western blot analysis of MBP isoform expression in CGT-KO $(\mathrm{KO})$ and control (Cont) cultures, showing that all isoforms of MBP were elevated in the mutants.
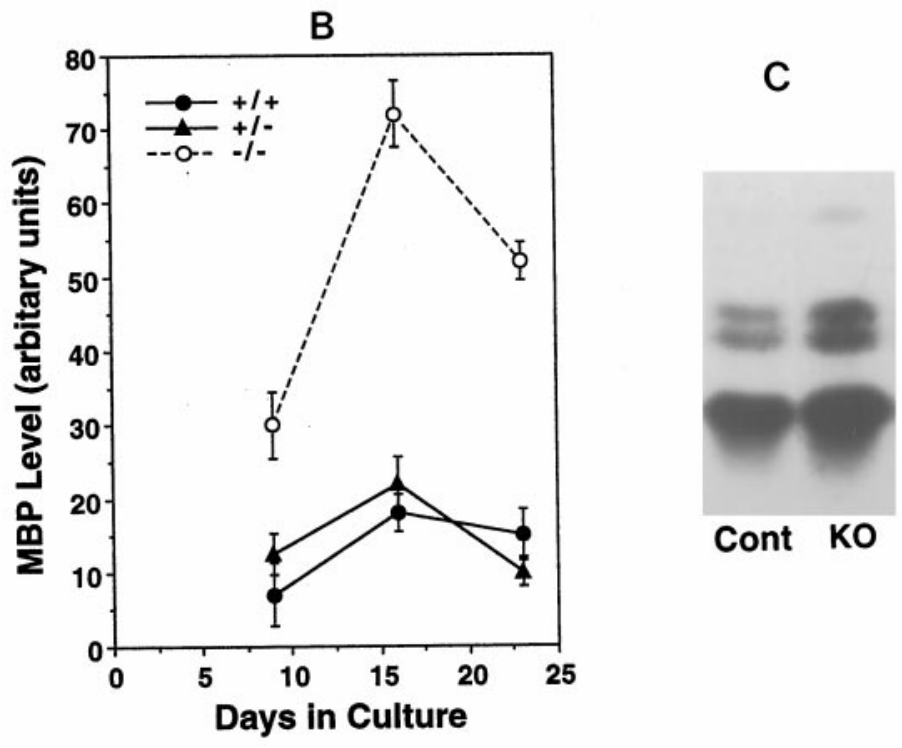

population size but rather to an enhancement in the timing and extent of their differentiation program.

\section{Oligodendrocyte differentiation is also enhanced in vivo in CGT-KO mice}

Next we asked whether the enhancement of OL differentiation observed in culture also occurs in vivo (Figs. 9,10). Using immunohistochemistry for MBP and in situ hybridization for PLP mRNA, we analyzed OL differentiation in mouse postnatal day 7 forebrains. The OL differentiation program is just beginning at this age in the corpus callosum; therefore any increases in OL number should be easily detectable. In addition, the analysis of forebrain provided for anatomical consistency with our studies in culture that used telencephalon. As expected, GalC, sulfatide $\left(\mathrm{R}-\mathrm{mAb}^{+}\right.$, $\left.\mathrm{O}^{+}\right)$, and POA $\left(\mathrm{O}^{+}\right)$were absent from CGT-KO brains (data not shown). MBP immunolabeling revealed more myelinated fibers in CGT-KO corpus callosum compared with controls (data not shown). Because an estimation of the number of $\mathrm{MBP}^{+}$OLs is difficult because of the background of highly immunolabeled myelinated fibers, we quantified these effects by counting PLP mRNA $^{+}$cells, which identified individual cells. When parallel sagittal sections from control and CGT-KO groups from the same litter were compared, we observed in the CGT-KO group a marked increase in the number of cells expressing PLP mRNA throughout

the corpus callosum and a wider spread of positive cells into the cortical region (Fig. 9). Although no marked differences in cell numbers were observed between wild-type and heterozygous mice, in the homozygous mutants, the numbers of OLs per section were approximately twofold more than that in the controls (Fig. 10). The increased number of PLP mRNA $^{+}$cells in the CGT-deficient brains was unlikely to be due to better survival of OLs since examination of condensed nuclei by Hoescht or propidium iodide staining (indicative of cell death) did not show any differences between the two groups at P7 (data not shown). We conclude that more OLs developed in the CGT-KO mice in vivo compared with wild-type mice, consistent with our findings in culture.

\section{DISCUSSION}

The molecular regulation of the onset of terminal differentiation is a key issue of cell and developmental biology. Galactocerebroside (GalC) and sulfatide are synthesized and transported to the outer leaflet of the oligodendrocyte (OL) plasma membrane at a critical point in differentiation, when OL progenitors cease to proliferate and commence terminal differentiation (Raff et al., 1978; Hardy and Reynolds, 1991; Pfeiffer et al., 1993). We hypothesized that OL surface "galactolipids such as galactocerebroside and sulfatide have functional roles in the regulation of 
A

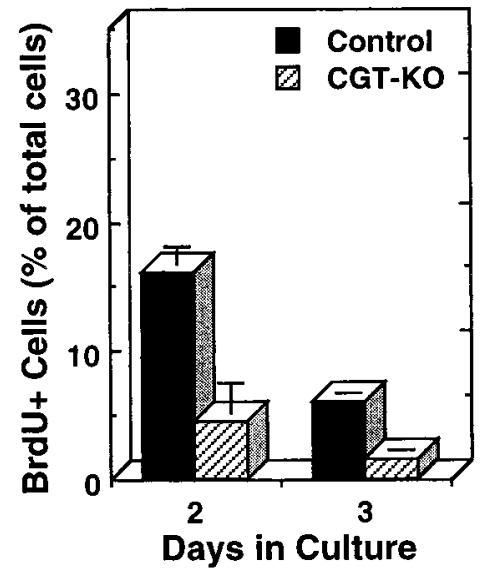

B

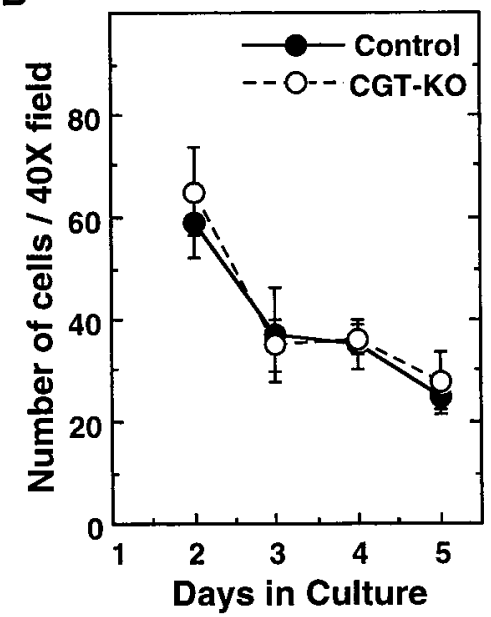

Figure 8. Comparison of the proliferation and survival of Pro-OLs in purified cultures from CGT-KO and control mice. $A$, Cells were analyzed 2 and $3 \mathrm{~d}$ after plating in $\mathrm{mN} 2$ after exposure to BrdU for the last $24 \mathrm{hr}$. The incorporation of BrdU was analyzed by immunolabeling of cultures and counting the percent of total cells that were $\mathrm{BrdU}^{+}$. No increase in proliferation was seen in CGT-KO progenitors (striped bars). In fact, an expected reduction is seen compared with control cultures (black bars) as a result of entry into postmitotic terminal differentiation earlier than in control populations. Error bars represent SEM $(n=3)$. $B$, The number of total live cells per field was determined by counting the nonpyknotic nuclei labeled with the Hoescht dye as a function of time in culture. No differences were observed between the control (solid line) and CGT-KO (dashed line) groups. Error bars represent SEM $(n=4-6)$.

oligodendrocyte differentiation and myelination by acting as sensors/transmitters of environmental information" (Bansal et al., 1988; Bansal and Pfeiffer, 1989). This hypothesis has been supported by our findings using anti-galactolipid antibody perturbation and biochemical inhibition of sulfatide synthesis (Bansal et al., 1988; Bansal and Pfeiffer, 1989, 1994a,b) (this report), as well as by a number of other observations related to the role of not only galactolipids but also gangliosides (for review, see Bansal et al., 1988; Coetzee et al., 1998; e.g., Diaz et al., 1978; Dorfman et al., 1979; Ranscht et al., 1982, 1987; Dyer and Benjamins, 1988; Pettmann et al., 1988; Wu and Ledeen, 1991; Yim et al., 1994). These studies demonstrate that the interaction of these galactolipids with the environment leads to biological responses. The present study analyzing OL development in a mouse unable to
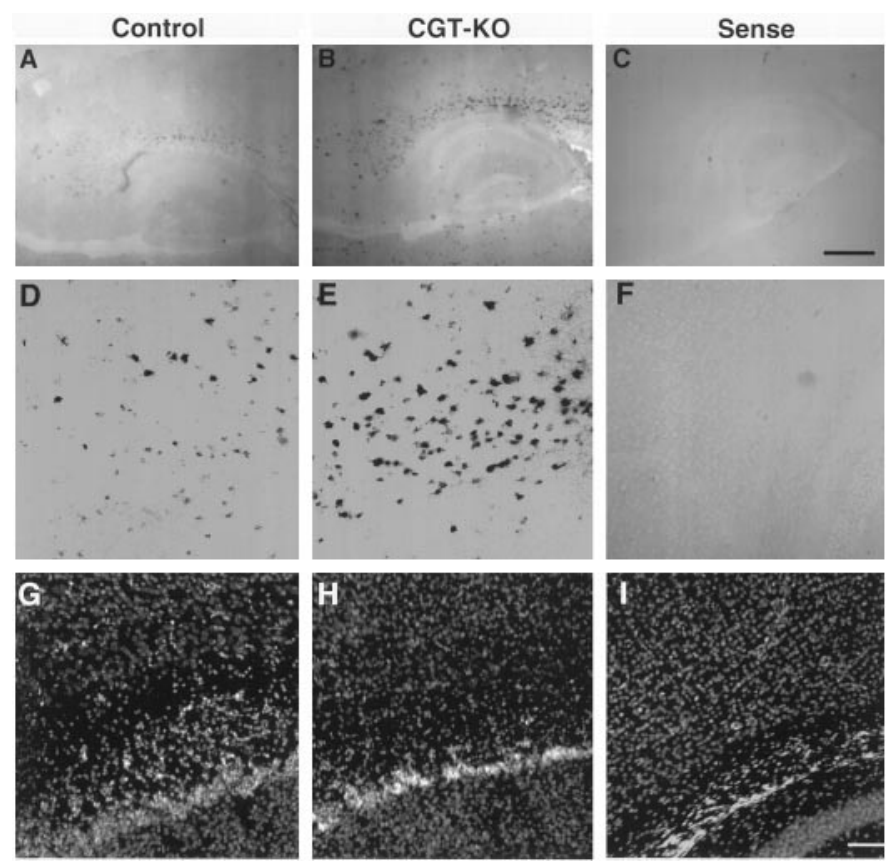

Figure 9. Enhancement of oligodendrocyte differentiation in vivo in CGT-KO mice. P7 forebrain sagittal sections taken from parallel regions of control $(A, D, G)$ and CGT-KO $(B, E, H)$ mice brains were analyzed by PLP mRNA in situ hybridization. PLP mRNA ${ }^{+}$cells in regions of the corpus callosum over the hippocampus are shown at low magnification $(A-C)$ and high magnification $(D-I)$. Sections hybridized with either antisense $(A, B, D, E)$ or sense (C, F) PLP cRNA probes were costained with Hoescht dye $(G, H, I)$ to show that similar brain regions of control and CGT-KO mice were analyzed. Representative sections show a higher number of PLP mRNA ${ }^{+}$cells in CGT-KO $(B, E)$ compared with control $(A, D)$ mice of the same age. Sections hybridized with sense cRNA probes showed no labeling. Scale bars: $A-C, 500 \mu \mathrm{m} ; D-I, 100 \mu \mathrm{m}$.

synthesize these lipids because of a targeted mutation of the ceramide galactosyltransferase gene (CGT-KO) provides additional, direct support for the hypothesis.

The principal observation of this study is that terminal differentiation of OLs is enhanced by the elimination of galactolipids whose synthesis is catalyzed by CGT, demonstrated by the marked increase in the number of terminally differentiated CGT-KO OLs compared with that of normal controls, both in culture and in vivo. Because the general pattern of differentiation, level of progenitor proliferation, and cell survival appear to be unaltered in the mutant cultures, we conclude that the increased number of OLs is caused by an increase in the propensity of late progenitors (Pro-OLs) to differentiate. Consistent with these data are the observations that CGT mRNA expression begins at the Pro-OL stage of the OL lineage and that POA (Sommer and Schachner, 1981; Bansal et al., 1992) expression is lost, indicating that POA is a lipid requiring CGT for its synthesis.

We now extend the original hypothesis to propose that $\mathrm{GalC}$ and/or sulfatide interact with external ligands and negatively regulate OL terminal differentiation (Fig. 11). Accordingly, the absence of GalC/sulfatide in the CGT-KO mouse precludes the instigation of the negative regulation, thus allowing terminal differentiation to proceed more efficiently. This hypothesis is also consistent with an arrest of the terminal differentiation of OL by the anti-galactolipid antibodies R-mAb (Bansal and Pfeiffer, 1989) and $\mathrm{O} 4$ (present study). The antibodies presumably mimic an in vivo endogenous ligand that constitutively activates the proposed 


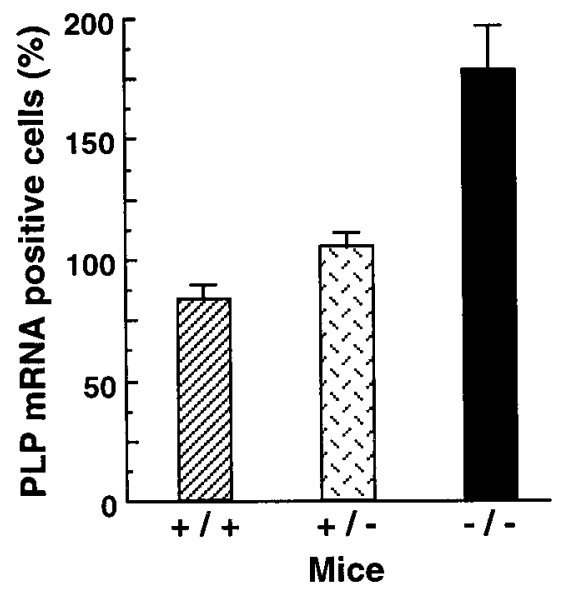

Figure 10. Quantification of the enhanced expression of PLP mRNA ${ }^{+}$ cells in vivo. P7 forebrain sagittal sections from control and CGT-KO mice were hybridized with an antisense PLP cRNA probe. All PLP mRNA positive cells in the cortical and corpus callosum region were counted for each section. Two to four sections each from 16 control $(+/+, 5 ;+/-, 12)$ and 9 homozygous mutant animals were counted. Comparisons of each control and CGT-KO were made on littermates. Control numbers (average of control for all $+/+$ and $+/-$ animals) were set to $100 \%$, and CGT-KO (-/-) levels are shown relative to that. Error bars represent SEM. The differences were statistically significant with $96 \%$ confidence limits using the Student's $t$ test.

negative regulatory pathway, blocking terminal differentiation. In fact, ligand binding to cell surface proteins can be mimicked by antibodies in a number of instances to produce transmembrane signals (for review, see Dyer, 1993): anti-integrin antibody activates integrin signaling (Coppolino et al., 1995); antibodies against the EGF or insulin receptors induce effects normally mediated by their ligands (Jacobs et al., 1978; Schreiber et al., 1981); anti- $\beta$ adrenergic receptor stimulates adenyl cyclase (Courand et al., 1981); anti-syndecan-1, a transmembrane proteoglycan, induces clustering of syndecan-1 and reorganization of the actin filaments (Carey et al., 1994); and antibodies to GM1 and CD59 lead to the accumulation of actin and tyrosine-phosphorylated proteins in glycolipid clusters (Harder and Simons, 1999).

The model therefore predicts the existence of a "ligand" that interacts with these galactolipids. In studies of both CGT-KO mice and antibody perturbation, alterations of OL differentiation occurred in highly enriched populations of OL progenitors. Therefore, soluble factors or extracellular matrix molecules secreted by OLs or the few remaining astrocytes in the cultures apparently provide the source of this ligand. It is, however, noteworthy that in each case (antibody perturbation and CGT-KO studies), the effects on differentiation were more pronounced in mixed primary cultures and/or in the presence of fetal calf serum, suggesting that the endogenous ligand concentration was increased in these conditions. This would indicate that a common molecule, whether secreted by OLs or astrocytes or provided via serum components, can serve as a source of the ligand.

Two observations suggest that sulfatide is the more likely candidate as the key cellular molecule in this regulation. First, treatment of enriched cultures of OLs with anti-sulfatide (O4$\mathrm{mAb}$ ), but not a true anti-GalC (O1 mAb) (Fig. 1), dramatically inhibited OL terminal differentiation. Second, sulfatide carries a negative charge and can therefore bind to positively charged proteins by electrostatic forces, a characteristic that may account for the large number of sulfatide-protein interactions (for review,

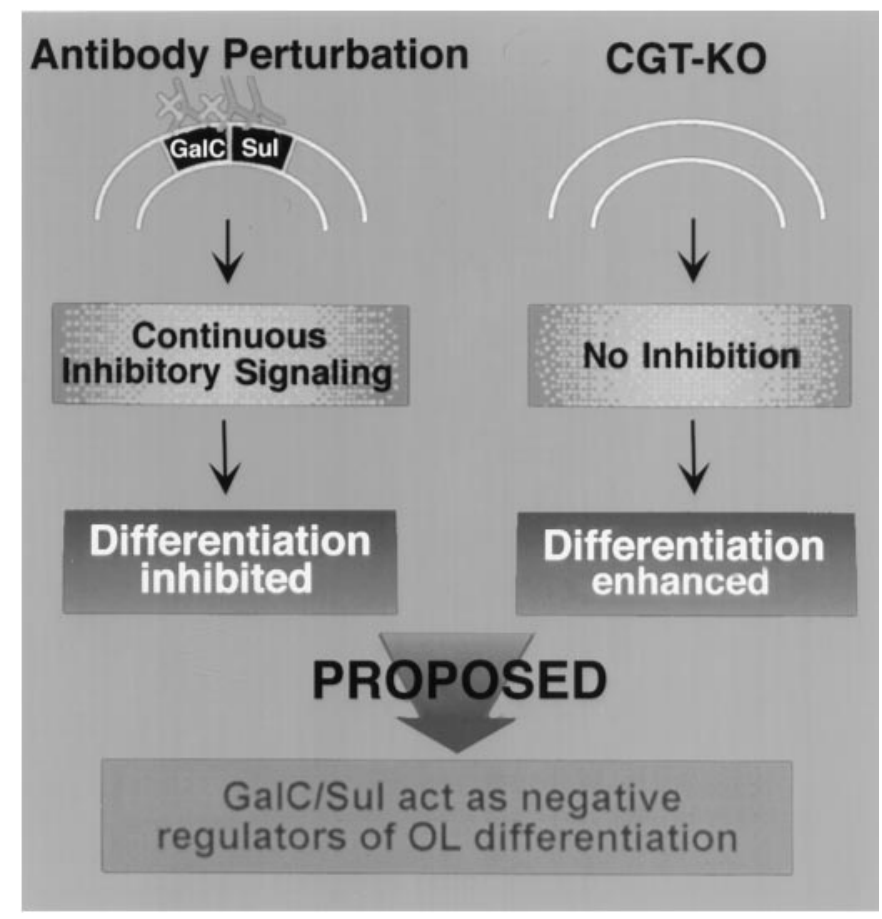

Figure 11. A model for the role of galactosphingolipids as negative regulators of oligodendrocyte terminal differentiation. Based on previous studies (Bansal and Pfeiffer, 1989) and Figure 1, the model suggests that specific anti-galactosphingolipid antibodies, presumably mimicking an external ligand, either directly or indirectly continuously activate negative regulatory pathways, thus inhibiting terminal differentiation of oligodendrocyte progenitors. In the studies of oligodendrocyte differentiation in the CGT-KO mice, the model suggests that the absence of GalC/sulfatide precludes the instigation of the negative regulation, thus allowing terminal differentiation to proceed more efficiently. Sul, Sulfatide.

see Vos et al., 1994). Of particular interest is a well documented role for sulfatide, but not for GalC, in adhesion with extracellular matrix molecules, such as tenascin-R/janusin/J-1, laminin, and thrombospondin (Roberts and Ginsburg, 1988; Pesheva et al., 1997), that are present in the CNS (McLoon et al., 1988; O'Shea et al., 1990; Bartsch et al., 1992) and are secreted by the OLs and/or astrocytes in culture (Oh and Yong, 1996; Pesheva et al., 1997).

What is the mechanism by which the negative signal is propagated? One view emanates from the observation that the binding of anti-GalC or anti-sulfatide to cells leads to an influx of $\mathrm{Ca}^{2+}$ (Dyer and Benjamins, 1990, 1991), perhaps via the activation of a novel type of $\mathrm{Ca}^{2+}$ channel (Joshi and Mishra, 1997). In addition, there is increasing evidence that a number of extracellular molecules induce sphingolipid hydrolysis and that their metabolic products, such as ceramide, sphingosine, and sphingosine-1phosphate, may act as mediators in signaling pathways leading to diverse responses (for review, see Hannun and Obeid, 1995; Testi, 1996; Riboni et al., 1997). These include cell proliferation, differentiation, or growth arrest and apoptosis, depending on cell type, cell compartment, and concentration of the metabolite. It is possible that GalC/sulfatide, like sphingomyelin, may serve as a source of these sphingolipid hydrolysis products.

Alternatively, galactosphingolipids could be involved indirectly by affecting the orientation and/or lateral movement of other outer leaflet, plasma membrane-signaling macromolecules. These signaling complexes may exist to bring together signaling molecules such as growth factor receptors, integrins, and cell adhesion mol- 
ecules, resulting in their activation and the onset of intracellularsignaling cascades. The absence of galactosphingolipids in the CGT-KO would be likely to affect the composition and/or geography of plasma membrane proteins and thus the functional biochemistry of the OL plasma membrane. Thus, GalC and sulfatide could operate by facilitating these clustering phenomena. Several structures are recognized that could participate in the formation of these signaling complexes, including caveolae (Liu et al., 1996; Mineo et al., 1996; Okamoto et al., 1998) and "lipid rafts" [lipidprotein detergent-insoluble glycolipid (DIG) complexes] enriched in glycolipids and glycosylphosphatidylinositol-anchored proteins (Kim et al., 1995; Koch et al., 1997; Simons and Ikonen, 1997; Harder and Simons, 1999). In fact, we have observed changes in the protein composition of DIGs prepared from CGT-KO mice compared with that of normal brains, suggesting the role of $\mathrm{GalC} /$ sulfatide in regulating such protein-lipid interactions (T. Kim, R. Bansal, and S. E. Pfeiffer, unpublished observations).

Lateral mobility of molecules in the plasma membrane could also facilitate the concentration of adhesion molecules at sites of cell-cell contact or of integrins at focal adhesion sites (Clark and Brugge, 1995) and thereby dramatically increase adhesion strength (Tozeren et al., 1992). Sulfatide may act as a primary or "coadhesion molecule" to bring together the ligand and the integrins to form a more stable adhesion/clustering/signaling complex. For example, OLs express several classes of integrins (Milner and ffrench-Constant, 1994) that can serve as receptors for the same ECM molecules that bind to sulfatide (above) and transduce signals to regulate OL adhesion and differentiation. In fact, integrin-mediated inhibition of OL differentiation (similar to that induced by anti-galactolipids) occurs in OL cultures treated with RGD peptide, a sequence in the ECM molecules recognized by the integrins (Cardwell and Rome, 1988; Malek-Hedayat and Rome, 1994). Similarly tenascin-R, which is secreted by OLs in culture (Pesheva et al., 1997), binds to both sulfatide and F3/F11/ contactin (Nörenberg et al., 1995) on the OL surface (Koch et al., 1997; Pesheva et al., 1997). F3 intern binds to Fyn, a nonreceptor tyrosine kinase that is implicated as an important signaling molecule in OL development and myelin formation (Osterhout et al., 1999; Umemori et al., 1999). The isolation of these components in the DIG complex from myelin (Koch et al., 1997) is suggestive of such an interaction compartment of the OL plasma membrane.

In summary, the present observation of an enhanced OL differentiation program in the absence of GalC and sulfatide, together with the previously reported myelin structural and functional abnormalities in the CGT-null mice, suggests that galactosphingolipids play dual roles, one as structural components of mature myelin and another as negative regulators of the OL differentiation program leading to myelinogenesis.

\section{REFERENCES}

Ausubel FM, Brent R, Kingston RE, Moore DD, Seidman JG, Smith JA, Struhl K (1991) Current protocols in molecular biology. New York: Wiley.

Bambrick LL, Grip A, Seenivasan V, Krueger BK, Yarowsky PJ (1996) Expression of glial antigens in mouse astrocytes: species differences and regulation in vitro. J Neurosci Res 46:305-315.

Bansal R, Pfeiffer SE (1989) Reversible inhibition of oligodendrocyte progenitor differentiation by a monoclonal antibody against surface galactolipids. Proc Natl Acad Sci USA 86:6181-6185.

Bansal R, Pfeiffer SE (1992) Novel stage in the oligodendrocyte lineage defined by reactivity of progenitors with $\mathrm{R}-\mathrm{mAb}$ prior to $\mathrm{O} 1$ antigalactocerebroside. J Neurosci Res 32:309-316.

Bansal R, Pfeiffer SE (1994a) Inhibition of protein and lipid sulfation in oligodendrocytes blocks biological responses to FGF-2 and retards cyto- architectural maturation, but not developmental lineage progression. Dev Biol 162:511-524.

Bansal R, Pfeiffer SE (1994b) Regulation of gene expression in mature oligodendrocytes by the specialized myelin-like membrane environment: antibody perturbation in culture with the monoclonal antibody R-mAb. Glia 12:173-179.

Bansal R, Pfeiffer SE (1997) FGF-2 converts mature oligodendrocytes to a novel phenotype. J Neurosci Res 50:215-228.

Bansal R, Gard AL, Pfeiffer SE (1988) Stimulation of oligodendrocyte differentiation in culture in the presence of a monoclonal antibody to sulfated glycolipid. J Neurosci Res 21:260-267.

Bansal R, Warrington AE, Gard AL, Ranscht B, Pfeiffer SE (1989) Multiple and novel specificities of monoclonal antibodies 01,04 , and R-mAb used in the analysis of oligodendrocyte development. J Neurosci Res 24:548-557.

Bansal R, Stefansson K, Pfeiffer SE (1992) Proligodendroblast antigen (POA), a developmental antigen expressed by A007/O4-positive oligodendrocyte progenitors prior to the appearance of sulfatide and galactocerebroside. J Neurochem 58:2221-2229.

Bansal R, Kumar M, Murray K, Morrison RS, Pfeiffer SE (1996) Regulation of FGF receptors in the oligodendrocyte lineage. Mol Cell Neurosci 7:263-275.

Bansal R, Kim T, Pfeiffer SE (1997) Importance of glycolipids in oligodendrocyte membrane biogenesis and maintenance: protein-lipid interactions. J Neurochem 69:95.

Bartsch S, Bartsch U, Dorries U, Faissner A, Weller A, Ekblom P, Schachner M (1992) Expression of tenascin in the developing and adult cerebellar cortex. J Neurosci 12:736-749.

Bosio A, Binczek E, Stoffel W (1996) Functional breakdown of the lipid bilayer of the myelin membrane in central and peripheral nervous system by disrupted galactocerebroside synthesis. Proc Natl Acad Sci USA 93:13280-13285.

Brown MC, Moreno MB, Bongarzone ER, Cohen PD, Soto EF, Pasquini JM (1993) Vesicular transport of myelin proteolipid and cerebroside sulfates to the myelin membrane. J Neurosci Res 35:402-408.

Cardwell MD, Rome LH (1988) RGD-containing peptides inhibit the synthesis of myelin-like membrane by cultured oligodendrocytes. J Cell Biol 107:1551-1559.

Carey DJ, Stahl RC, Cizmeci-Smith G, Asundi VK (1994) Syndecan-1 expressed in schwann cells causes morphological transformation and cytoskeletal reorganization and associates with actin during cell spreading. J Cell Biol 124:161-170.

Chomczynski P, Sacchi N (1987) Single-step method of RNA isolation by acid guanidinium thiocyanate-phenol-chloroform extraction. Anal Biochem 162:156-159.

Clark EA, Brugge JS (1995) Integrins and signal transduction pathways: the road taken. Science 268:233-239.

Coetzee T, Fujita N, Dupree J, Shi R, Blight A, Suzuki K, Popko B (1996) Myelination in the absence of galactocerebroside and sulfatide: normal structure with abnormal function and regional instability. Cell 86:209-219.

Coetzee T, Suzuki K, Popko B (1998) New perspectives on the function of myelin galactolipids. Trends Neurosci 21:126-130.

Coppolino M, Leung-Hagesteijn C, Dedhar S, Wilkins J (1995) Inducible interaction of integrin $\alpha_{2} \quad \beta_{1}$ with calreticulin. J Biol Chem 270: 23132-23138.

Courand P-O, Delavier-Klutchko C, Durieu-Trautmann O, Strosberg AD (1981) Antibodies raised against $\beta$-adrenergic receptors stimulate adenyl cyclase. Biochem Biophys Res Commun 99:1295-1302.

Diaz M, Bornstein MB, Raine CS (1978) Disorganization of myelinogenesis in tissue culture by anti-CNS antiserum. Brain Res 154:231-239.

Dorfman SH, Fry JM, Silberberg DH (1979) Antiserum induced myelination inhibition in vitro without complement. Brain Res 177:105-114.

Duchala CS, Asotra K, Macklin WB (1995) Expression of cell surface markers and myelin proteins in cultured oligodendrocytes from neonatal brain of rat and mouse: a comparative study. Dev Neurosci 17:70-80.

Dupree JL, Coetzee T, Blight A, Suzuki K, Popko B (1998) Myelin galactolipids are essential for proper node of Ranvier formation in the CNS. J Neurosci 18:1642-1649.

Dyer CA (1993) Novel oligodendrocyte transmembrane signaling systems: investigation utilizing antibodies as ligands. Mol Neurobiol 7:1-22.

Dyer CA, Benjamins JA (1988) Antibody to galactocerebroside alters organization of oligodendroglial membrane sheets in culture. J Neurosci 8:4307-4318.

Dyer CA, Benjamins JA (1990) Glycolipids and transmembrane signaling: 
antibodies to galactocerebroside cause a calcium influx in oligodendrocytes. J Cell Biol 111:625-633.

Dyer CA, Benjamins JA (1991) Galactocerebroside and sulfatide independently mediate $\mathrm{Ca}^{2+}$ responses in oligodendrocytes. J Neurosci Res 30:699-711.

Eisenbarth GS, Walsh FS, Nirenberg M (1979) Monoclonal antibody to a plasma membrane antigen of neurons. Proc Natl Acad Sci USA 76:4913-4917.

Fanarraga ML, Sommer I, Griffiths IR (1995) O-2A progenitors of the mouse optic nerve exhibit a developmental pattern of antigen expression different from the rat. Glia 15:95-104.

Fredman P, Mattsson L, Andersson K (1988) Characterization of the binding epitope of a monoclonal antibody to sulphatide. Biochem $\mathrm{J}$ 251:17-22.

Fuss B, Baba H, Phan T, Tuohy VK, Macklin WB (1997) Phosphodiesterase 1, a novel adhesion molecule and/or cytokine involved in oligodendrocyte function. J Neurosci 17:9095-9103.

Gard AL, Pfeiffer SE (1989) Oligodendrocyte progenitors isolated directly from developing telencephalon at a specific phenotypic stage: myelinogenic potential in defined environment. Development 106:119-132.

Hannun YA, Obeid LM (1995) Ceramide: an intracellular signal for apoptosis. Trends Biochem Sci 20:73-77.

Harder T, Simons K (1999) Clusters of glycolipid and glycosylphosphatidylinositol-anchored proteins in lymphoid cells: accumulation of actin regulated by local tyrosine phosphorylation. Eur J Immunol 29:556-562.

Hardy R, Reynolds R (1991) Proliferation and differentiation potential of rat forebrain oligodendroglial progenitors both in vitro and in vivo. Development 111:1061-1080.

Jacobs S, Chang KJ, Cuatrecasas P (1978) Antibodies to purified insulin receptor have insulin-like activity. Science 200:1283-1284.

Joshi PG, Mishra S (1997) A novel type of $\mathrm{CA}^{2+}$ channel in U-87 MG cells activated by anti-galactocerebroside. Life Sci 62:469-477.

Jung M, Sommer I, Schachner M, Nave K-A (1996) Monoclonal antibody O10 defines a conformationally sensitive cell-surface epitope of proteolipid protein (PLP): evidence that PLP misfolding underlies dysmyelination in mutant mice. J Neurosci 16:7920-7929.

Kim T, Fiedler K, Madison D, Krüger WH, Pfeiffer SE (1995) Cloning and characterization of MVP17, a developmentally regulated myelin protein in oligodendrocytes. J Neurosci Res 42:413-422.

Koch T, Brugger T, Bach A, Gennarini G, Trotter J (1997) Expression of the immunoglobulin superfamily cell adhesion molecule F3 by oligodendrocyte-lineage cells. Glia 19:199-212.

Laird PW, Zijderveld A, Linders K, Rudnicki MA, Jaenisch R, Berns A (1991) Simplified mammalian DNA isolation procedure. Nucleic Acids Res 19:4293-4294.

Liu P, Ying Y, Ko Y-G, Anderson RGW (1996) Localization of plateletderived growth factor-stimulated phosphorylation cascade to caveolae. J Biol Chem 271:10299-10303.

Malek-Hedayat S, Rome LH (1994) Expression of a $\beta 1$-related integrin by oligodendroglia in primary culture: evidence for a functional role in myelination. J Cell Biol 124:1039-1046.

McCarthy KD, DeVellis J (1980) Preparation of separate astroglial and oligodendroglial cell cultures from rat cerebral tissue. J Cell Biol 85:890-902.

McLoon SC, McLoon LK, Palm SL, Furcht LT (1988) Transient expression of laminin in the optic nerve of the developing rat. J Neurosci 8:1981-1990.

Miller RH (1996) Oligodendrocyte origins. Trends Neurosci 19:92-96.

Milner R, ffrench-Constant C (1994) A developmental analysis of oligodendroglial integrins in primary cells: changes in $\alpha \mathrm{v}$-associated $\beta$ subunits during differentiation. Development 120:3497-3506.

Mineo C, James GL, Smart EJ, Anderson RGW (1996) Localization of epidermal growth factor-stimulated ras/raf-1 interaction to caveolae membrane. J Biol Chem 271:11930-11935.

Nörenberg U, Hubert M, Brümmendorf T, Tárnok A, Rathjen FG (1995) Characterization of functional domains of the tenascin-R (restrictin) polypeptide: cell attachment site, binding with F11, and enhancement of F11-mediated neurite outgrowth by tenascin-R. J Cell Biol 130:473-484.

Oh LYS, Yong VW (1996) Astrocytes promote process outgrowth by adult human oligodendrocytes in vitro through interaction between bFGF and astrocyte extracellular matrix. Glia 17:237-253.

Okamoto T, Schlegel A, Scherer PE, Lisanti MP (1998) Caveolins, a family of scaffolding proteins for organizing "preassembled signaling complexes" at the plasma membrane. J Biol Chem 273:5419-5422.
O'Shea KS, Rheinheimer JST, Dixit VM (1990) Deposition and role of thrombospondin in the histogenesis of the cerebellar cortex. J Cell Biol 110:1275-1283.

Osterhout DJ, Wolven A, Wolf RM, Resh MD, Chao MV (1999) Morphological differentiation of oligodendrocytes requires activation of Fyn tyrosine kinase. J Cell Biol 145:1209-1218.

Pasquini JM, Guarna MM, Besio-Moreno MA, Iturregui MT, Oteiza PI, Soto EF (1989) Inhibition of the synthesis of glycosphinogolipids affects the translocation of proteolipid protein to the myelin membrane. J Neurosci Res 22:289-296.

Pesheva P, Gloor S, Schachner M, Probstmeier R (1997) Tenascin-R is an intrinsic autocrine factor for oligodendrocyte differentiation and promotes cell adhesion by a sulfatide-mediated mechanism. J Neurosci 17:4642-4651.

Pettmann B, Manthorpe M, Varon S (1988) Ganglioside GM1 actions on cell-substratum adhesion and DNA synthesis by cultured astroglial cells. J Neurosci Res 20:442-450.

Pfeiffer SE, Warrington AE, Bansal R (1993) The oligodendrocyte and its many cellular processes. Trends Cell Biol 3:191-197.

Raff MC, Mirsky R, Fields KL, Lisak RP, Dorfman SH, Silberberg DH, Gregson NA, Leibowitz S, Kennedy MC (1978) Galactosylcerebroside is a specific cell-surface antigenic marker for oligodendrocytes in culture. Nature 274:813-816.

Ranscht B, Clapshaw PA, Price J, Noble M, Seifert W (1982) Development of oligodendrocytes and Schwann cells studied with a monoclonal antibody against galactocerebroside. Proc Natl Acad Sci USA 79:2709-2713.

Ranscht B, Wood P, Bunge RP (1987) Inhibition of in vitro peripheral myelin formation by monoclonal anti-galactocerebroside. J Neurosci 7:2936-2947.

Riboni L, Viani P, Bassi R, Prinetti A, Tettamanti G (1997) The role of sphingolipids in the process of signal transduction. Prog Lipid Res 36:153-195.

Roberts DD, Ginsburg V (1988) Sulfated glycolipids and cell adhesion. Arch Biochem Biophys 267:405-415.

Schreiber AB, Lax I, Yarden Y, Eshhar Z, Schlessinger J (1981) Monoclonal antibodies against receptor for epidermal growth factor induce early and delayed effects of epidermal growth factor. Proc Natl Acad Sci USA 78:7535-7539.

Simons K, Ikonen E (1997) Sphingolipid-cholesterol rafts in membrane trafficking and signalling. Nature 387:569-572.

Singh H, Pfeiffer SE (1985) Myelin-associated galactolipids in primary cultures from dissociated fetal rat brain: biosynthesis, accumulation, and cell surface expression. J Neurochem 45:1371-1381.

Sommer I, Schachner M (1981) Monoclonal antibodies (O1 to O4) to oligodendrocyte cell surfaces: an immunocytological study in the central nervous system. Dev Biol 83:311-327.

Stoffel W, Bosio A (1997) Myelin glycolipids and their function. Curr Opin Neurobiol 7:654-661.

Testi R (1996) Sphingomyelin breakdown and cell fate. Trends Biochem Sci 21:468-471.

Tozeren A, Sung KL, Sung LA, Dustin ML, Chan PY, Springer TA, Chien S (1992) Micromanipulation of adhesion of Jurket cell to a planar bilayer membrane containing lymphocyte function-associated antigen 3 molecules. J Cell Biol 116:997-1006.

Umemori H, Kadowaki Y, Hirosawa K, Yoshida Y, Hironaka K, Okano H, Yamamoto T (1999) Stimulation of myelin basic protein gene transcription by Fyn tyrosine kinase for myelination. J Neurosci 19:1393-1397.

van der Bijl P, Strous GJ, Lopes-Cardozo M, Thomas-Oatest J, van Meer G (1996) Synthesis of non-hydroxy-galactosylceramides and galactosyldiglycerides by hydroxy-ceramide galactosyltransferase. Biochem J 317:589-597.

Vos JP, Lopes-Cardozo M, Gradella BM (1994) Metabolic and functional aspects of sulphogalactolipids. Biochim Biophys Acta 1211:125-149.

Warrington AE, Pfeiffer SE (1992) Proliferation and differentiation of $\mathrm{O} 4+$ oligodendrocytes in postnatal rat cerebellum: analysis in unfixed tissue slices using anti-glycolipid antibodies. J Neurosci Res 33:338-353.

Wu G, Ledeen RW (1991) Stimulation of neurite outgrowth in neuroblastoma cells by neuraminidase: putative role of GM1 ganglioside in differentiation. J Neurochem 56:95-104.

Yim SH, Farrer RG, Hammer JA, Yavin E, Quarles RH (1994) Differentiation of oligodendrocytes cultured from developing rat brain is enhanced by exogenous GM3 ganglioside. J Neurosci Res 38:268-281. 